\title{
Estilos estruturais e evolução tectônica da porção mineira da bacia proterozóica do São Francisco
}

\author{
Júlio César Carvalho Coelho ${ }^{1,2}$, Marcelo Augusto Martins-Neto ${ }^{2,3}$ \& Marcelo S. Marinho ${ }^{2}$
}

\begin{abstract}
Resumo A Bacia do São Francisco foi submetida durante o tempo geológico a eventos tectônicos de diferentes intensidades e direções de transporte. A cada evento tectônico associa-se um conjunto de estruturas característico. O primeiro, iniciado há cerca de 1300-1200 Ma nos domínios da Faixa Brasília e há cerca de 900 Ma nos domínios da Faixa Araçuaí, foi um evento distensivo responsável pela formação de duas bacias do tipo rifte/margem passiva, uma a oeste e outra a leste. A este evento associa-se um conjunto de falhas normais, observadas em sísmica, na base de cada uma dessas bacias. O segundo grande evento foi transpressivo, afeta, sobretudo, a Seqüência Canastra/Paranoá, sendo caracterizado por uma série de falhas transcorrentes de direção NE-SW. O terceiro evento está relacionado à Orogenia Brasiliana, tendo evoluído entre 740 e 530 Ma. Ele foi responsável pela formação de uma bacia do tipo foreland e de dois cinturões de dobramento e cavalgamento. O primeiro a oeste, com dobras e falhas de empurrão com vergência para leste chegando a envolver até o embasamento na borda da bacia e com um domínio thin-skinned. O segundo, a leste, com as dobras e falhas de empurrão com vergência para oeste.
\end{abstract}

Palavras-chave: Bacia do São Francisco, estruturas, tectônica, sísmica.

\begin{abstract}
Structural Styles and Tectonic Evoluction Phase of the Proterozoic São Francisco Basin in Minas Gerais State, Brazil. The São Francisco basin was submitted during its evolution to distinct tectonic events in different directions and intensities. Each event can be associated to a characteristic group of structures. The first event had a distensive character and started at the Faixa Brasilia domain at about 1300$1200 \mathrm{Ma}$ and in the Faixa Araçuaí domain around $900 \mathrm{Ma}$. This distentional event resulted on the formation of two rift-to-passive margin basins, located respectively at the western and eastern sides of the São Francisco craton. Normal faults mapped in seismic sections record the rift stage of the basin. The second tectonic event was transpressive, produced a group of NE-SW strike-slip faults, which affect mainly the Canastra/Paranoá Sequence. The third event is related to the Brasiliano orogeny and evolved from about 740 to $530 \mathrm{Ma}$. It was responsible for the formation of a foreland basin and two thrust-and-fold belts. The first belt, in the western domain of the São Francisco basin, was built-up by a group of folds and faults with vergency to the east, involving the basement, and developing a thin-skinned domain. The second one, in the eastern domain, was built-up by a western verging group of folds and faults.
\end{abstract}

Keywords: São Francisco Basin, structures, tectonic, seismic.

INTRODUÇÃo Muitos estudos já foram realizados na Bacia do São Francisco, em toda sua extensão, principalmente nas regiões de borda, onde a tectônica deformadora permite uma exposição mais completa da sucessão sedimentar e acervo estrutural. Na porção intracratônica, região central da bacia, os afloramentos são menos abundantes e contêm somente rochas mais jovens do Neoprotezóico (Grupo Bambuí), Paleozóico (Grupo Santa Fé) e Mesozóico (grupos Areado, Mata da Corda e Urucuia) (Tabela 1).

Pretende-se apresentar neste trabalho uma análise dos estilos estruturais presentes na região oeste da Bacia do São Francisco em Minas Gerais (Fig. 1), incluindo uma visão dos diferentes estilos estruturais dentro das etapas evolutivas da bacia, à luz de novas ferramentas até então indisponíveis ou muito pouco di- vulgadas (Romeiro Silva et al. 1998, Fugita \& Clark 2001, Martins-Neto 2005, Romeiro Silva \& Zalán 2005, Coelho et al. 2005), principalmente os dados sísmicos e de poços adquiridos pela Petrobras durante as décadas de 80 e 90, disponibilizados pela ANP (Agência Nacional do Petróleo) para fins acadêmicos (Fig. 2).

A interpretação sísmica, associada com dados de um poço e de afloramentos, possibilitou o reconhecimento de diferentes grupos de estruturas que são característicos de diferentes momentos dentro da evolução tectônica da bacia, bem como de quatro seqüências deposicionais de primeira ordem: Espinhaço, Canastra/Paranoá, Macaúbas e Bambuí, além de uma unidade estratigráfica, Seqüência Vazante, cuja idade e correlação com as demais ainda são incertas. As seqüências Canastra/Paranoá, Vazante e Bambuí compuse-

1 - Petróleo Brasileiro S/A - Petrobras, Rio de Janeiro (RJ), Brasil. E-mail: julio.cesar@petrobras.com.br

2 - Departamento de Geologia, Escola de Minas, Universidade Federal de Ouro Preto, Ouro Preto (MG), Brasil.

3 - NUPETRO - Núcleo de Geologia do Petróleo, Fundação Gorceix, Ouro Preto (MG), Brasil. E-mail: marcelo@nupetro.com.br 


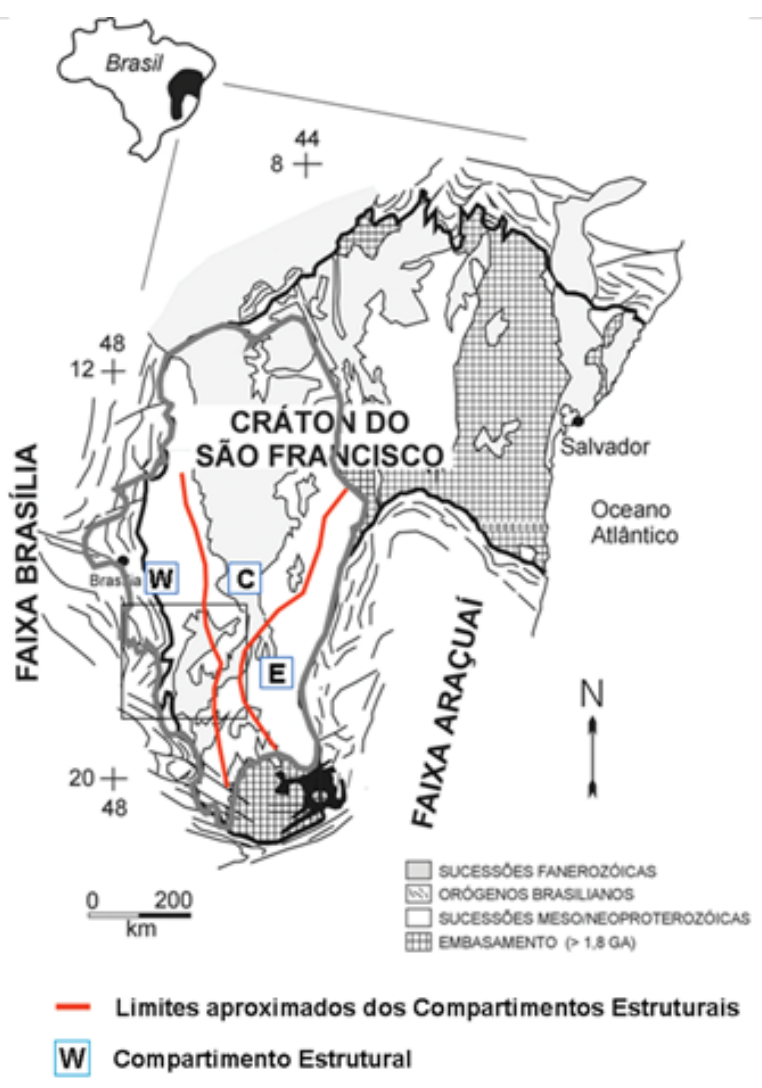

Figura 1 - Mapa de localização da área estudada (retângulo) no contexto regional do Cráton do São Francisco. Observar os limites, aproximados, da compartimentação estrutural da bacia, $W, C e$ E. Modificado de Alkmim \& Marshak (1998). ram o foco deste trabalho (Tab. 1, Fig. 3). As seqüências Espinhaço e Macaúbas não foram abordadas em detalhe, por ocorrerem na porção leste da bacia, fora da área de foco deste estudo. As seqüências mais jovens não foram contempladas neste estudo por terem sido depositadas após o último grande evento tectônico que afetou a Bacia do São Francisco, o Ciclo Brasiliano, e, conseqüentemente, sendo muito pouco ou quase nada afetadas estruturalmente. Além disso, por se tratar de depósitos sedimentares rasos estão fora da resolução da sísmica estudada.

Algumas vezes, observam-se estruturas mais antigas sendo reativadas em eventos posteriores ou servindo de ponto de nucleação de novas estruturas. Cada um desses grupos de estruturas afeta determinadas seqüências sedimentares, além do embasamento, passando pela Seqüência Canastra/Paranoá, do Meso e Neoproterozóico, em suas diversas fases na borda oeste, e seqüências Espinhaço e Macaúbas na borda leste, chegando a atingir a Seqüência Bambuí, Neoproterozóico (Tab. 1, Fig. 3) (Martins-Neto \& Alkmim 2001, Martins-Neto 2005).

Por enfocar a bacia neoproterozóica do São Francisco, no sentido de Martins-Neto \& Alkmim (2001), este trabalho considera como embasamento o conjunto de rochas que inclui as infra e supracrustais mais velhas que $1,8 \mathrm{Ga}$, bem como os depósitos pertencentes à Tafrogênese Estateriana (Espinhaço e Arai, Brito-Neves et al. 1996).

METODOLOGIA E BASE DE DADOS O presente estudo integra dados de diferentes fontes, com ênfase na interpretação das linhas sísmicas 2D disponibiliza-

Tabela 1 - Seqüências sedimentares pós-1,8 Ga encontradas na região estudada da Bacia do São Francisco. Modificado de Martins-Neto \& Alkmim (2001). (1) Martins-Neto (1998, 2000), (2) Martins-Neto et al. (2001), (3) Dardenne (2000), (4) Pereira (1992), (5) Pimentel et al. (1999, 2000), (6) Martins-Neto \& Hercos (2002), (7) Pedrosa-Soares et al. (2001), (8) Martins-Neto et al. (1997), (9) Castro \& Dardenne (2000), (10) Sgarbi et al. (2001), (11) Sawasato (1995)

\begin{tabular}{c|c|c|c|c}
\hline Seqüência & Idade (Ma) & Tipo de Bacia & Litoestratigrafia & Referências \\
\hline Areado/Mata da Corda/Urucuia & $140 / 70$ & sinéclise & Grupos Areado/Mata da Corda/Urucuia & 10,11 \\
\hline Santa Fé & $350 / 270$ & sinéclise & Grupo Santa Fé & 10 \\
\hline Bambuí & $790 / 600$ & foreland & Grupos Bambuí, Vazante e correlatos & $2,3,8,9$ \\
\hline Macaúbas & $950 / 650$ & rifte/margem passiva & Grupo Macaúbas & $2,5,6,7$ \\
\hline Canastra/Paranoá & $1300 / 950$ & rifte/margem passiva & Grupos Canastra e Paranoá & $3,4,5$ \\
\hline
\end{tabular}




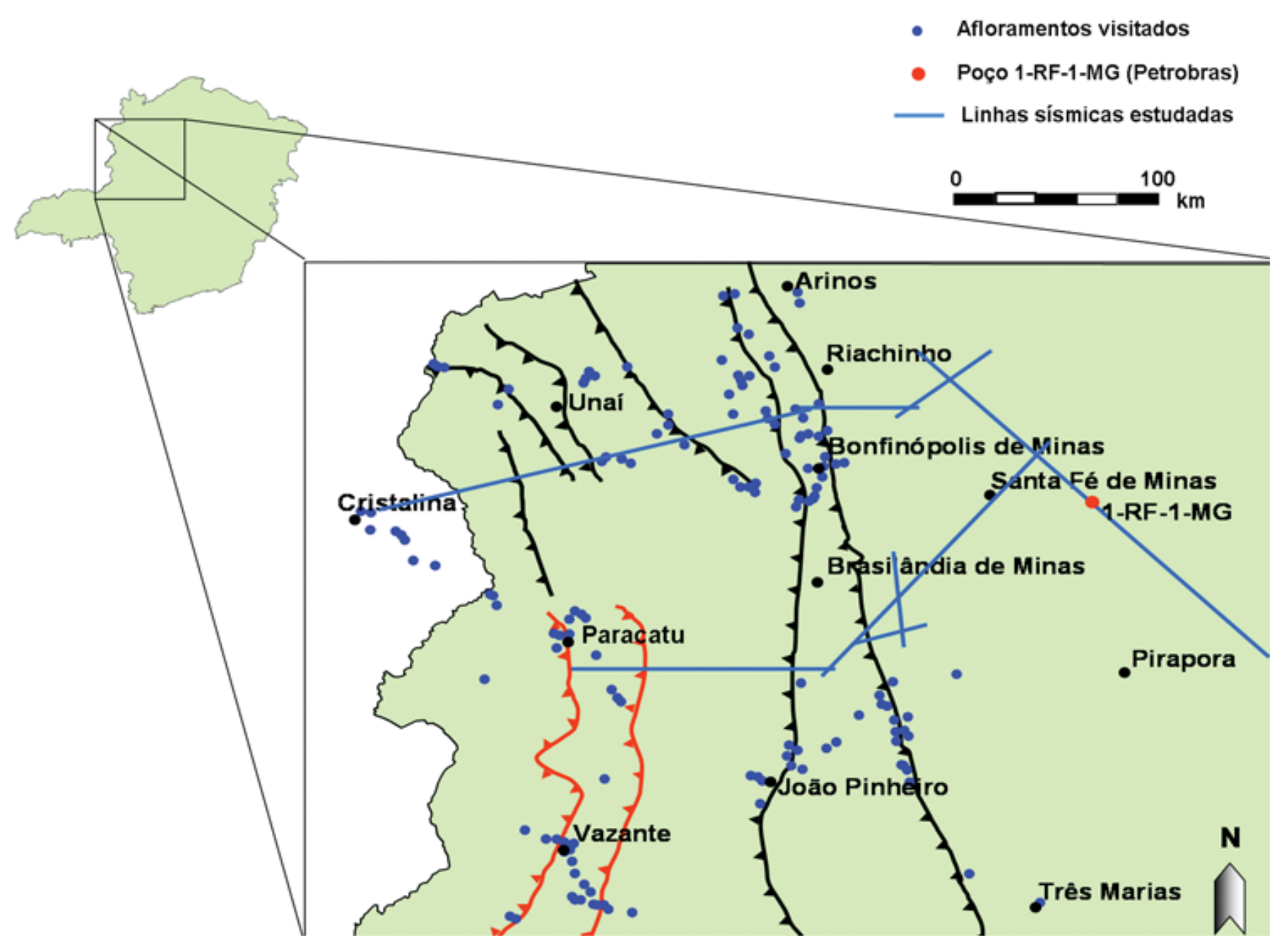

Figura 2 - Mapa da área estudada mostrando a localização do poço 1-RF-1-MG e das linhas sísmicas utilizadas, bem como dos afloramentos visitados.

das e do poço 1-RF-1-MG, liberados pela ANP-Agência Nacional do Petróleo para esse fim, bem como na amarração desses dados com a geologia de superfície (Fig. 2).

O primeiro passo foi a amarração do poço 1-RF1-MG à sísmica. Para isto, foi gerado um sismograma sintético usando o programa Syntool (Landmark); efetuada calibração da função velocidade $\mathrm{x}$ profundidade usando os perfis sônicos e checkshots; determinados topos litoestratigráficos e quebras nos perfis elétricos do poço, assim como a calibragem dos marcos elétricos e litológicos com o sinal sísmico.

Em seguida, efetuou-se a interpretação das linhas sísmicas supracitadas por meio do software Seisworks 2D (Landmark) com o rastreamento dos principais marcos/horizontes sismoestratigráficos e falhas. Com isso, esses marcos/horizontes sismoestratigráficos e falhas mapeadas foram amarrados à geologia de superfície.

Nessa etapa, foram realizadas sete viagens ao campo totalizando 40 dias de trabalho e 174 afloramentos descritos (Fig. 2).

Os dados coletados foram então lançados, georreferenciados e interpretados em base SIG no software
ArcView. Os dados estruturais foram tratados por meio do software StereoNet.

Pretende-se mostrar a seguir parte dos resultados obtidos neste estudo, tendo um enfoque maior na borda oeste, onde foram realizadas as etapas de campo.

QUADRO REGIONAL A Bacia do São Francisco cobre toda a porção sul do cráton homônimo e encerra, em seu registro estratigráfico, sucessivos ciclos bacinais de primeira ordem posteriores a $1,8 \mathrm{Ga}(\mathrm{Alkmim} \&$ Martins-Neto 2001). A porção cratônica da bacia possui cerca de $500.000 \mathrm{~km}^{2}$ e engloba parte dos estados de Minas Gerais, Bahia e Goiás. Neste estudo, será enfocada a região oeste da sua porção mineira (Figs. 1 e 2).

Grupos de estruturas diferentes podem ser observados tanto em superfície quanto em subsuperfície e podem ser associados aos diferentes eventos tectônicos aos quais a bacia foi submetida durante o tempo geológico (Fig. 3).

Estratigrafia e tectônica formadora As unidades estratigráficas envolvidas neste estudo, como justificado na introdução deste trabalho, são as seqüências deposicionais de primeira ordem (i) Canastra/Paranoá, do 


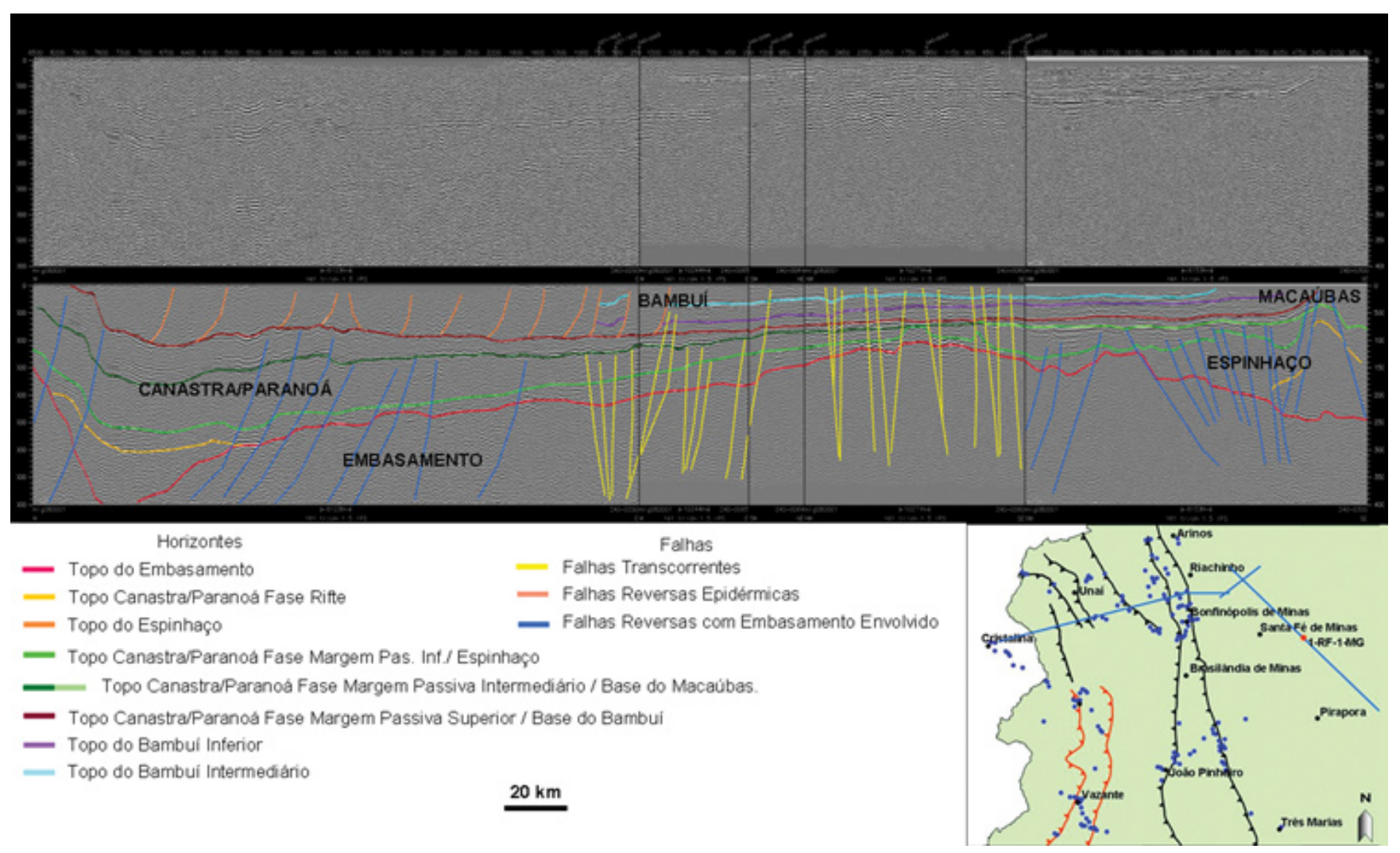

Figura 3 - Seção sísmica em tempo (TWT), do domo de Cristalina/GO, a oeste, passando pelo centro da bacia, e chegando ao flanco oeste da Serra da Água Fria, na borda leste da Bacia do São Francisco, mostrando os horizontes estratigráficos mapeados, bem como os diferentes estilos estruturais reconhecidos. Observar a base da Seqüência Bambui aflorando próximo às extremidades oeste e leste da seção, bem como a coincidência dessa feição com o descolamento basal da deformação epidérmica na metade oeste da seção.

Meso e Neoproterozóico, (ii) Vazante, de idade indefinida, e (iii) Bambuí, do Neoproterozóico (Tab. 1, Fig. 3) (Martins-Neto \& Alkmim 2001, Martins-Neto 2005).

A primeira seqüência deposicional reconhecida está associada ao início do ciclo divergente da bacia que levou à quebra do Supercontinente Rodínia (Brito Neves et al. 1993, Pedrosa-Soares \& WiedemannLeonardos 2000, Alkmim et al. 2001, Martins-Neto et al. 2001, Pedrosa-Soares et al. 2001). O processo de rifteamento que teria levado ao desenvolvimento de bacias do tipo rifte/margem passiva em ambos os lados do Paleocontinente São Francisco foi diacrônico. A oeste há cerca de 1,3-1,2 Ga implantou-se a bacia Canastra/ Paranoá e a leste, há cerca de $0,9 \mathrm{Ga}$, a bacia Macaúbas (Martins-Neto et al. 1997, 2001, Dardenne 2000, Martins-Neto \& Hercos 2002, Alkmim et al. 2001, PedrosaSoares et al. 2001).

A porção aflorante da Seqüência Canastra/ Paranoá é composta basicamente por arenitos e pelitos, com alguma contribuição carbonática (Dardenne 1978a, 1981, 2000). Reconhecem-se, em sísmica, fases deposicionais distintas, cada uma com suas sismofácies características (Martins-Neto 2005).

Os sedimentos da fase rifte da bacia Canastra/ Paranoá (Figs. 3 e 4), por tratarem-se dos mais antigos da bacia, estimados em cerca de 1300-1200 Ma (Dardenne 2000, Pimentel et al. 2000, Martins-Neto \& Alkmim 2001), não possuem registro em afloramentos na região estudada, e na literatura muito pouco foi descrito a respeito. Martins-Neto \& Alkmim (2001) sugerem que os Conglomerados São Miguel e depósitos sedimentares associados poderiam ser considerados como os representantes aflorantes dessa fase deposicional.

Acima dessa seqüência rifte, um conjunto de seqüências de margem passiva completa essa etapa tectono-sedimentar (Martins-Neto \& Alkmim 2001, Martins-Neto 2005). Essas seqüências teriam sido depositadas, na borda oeste (bacia Canastra/Paranoá), no período de 1200 Ma a $740 \mathrm{Ma}$ (Dardenne 2000, Pimentel et al. 1999, 2000, Martins-Neto et al. 2001, Martins-Neto \& Alkmim 2001). A idade mínima de 740 Ma é especulativa, na medida em que é baseada na idade máxima da Seqüência Bambuí. As idades de 950 Ma (Pimentel et al. 1999, 2000) para os arcos magmáticos mais antigos da Faixa Brasília indicam que pelo menos parte da margem passiva Canastra/Paranoá se desenvolveu em contexto de retroarco. O mapeamento sísmico (Fig. 3) mostra que, nas latitudes de abrangência deste trabalho, os depósitos da margem passiva Canastra/Paranoá estendem-se por sobre o Cráton do São Francisco, 
encobertos pelas seqüências Macaúbas e Bambuí, até próximo aos domínios da Serra da Água Fria.

Já na borda leste, a fase margem passiva da bacia Macaúbas foi depositada no período de 850 a 630 Ma (Pedrosa-Soares et al. 2000, Martins-Neto et al. 2001, Martins-Neto \& Alkmim 2001).

Um sistema de margem ativa associado à zona de subducção tem seus registros em ambas as faixas móveis que limitam a Bacia do São Francisco. Na Faixa Brasília, essa fase é representada pela Seqüência Araxá/ Ibiá, cujos registros indicam idades de 950 a $650 \mathrm{Ma}$ (Dardenne 2000, Pimentel et al. 1999, 2000, MartinsNeto \& Alkmim 2001). Na Faixa Araçuaí a leste, Pedrosa-Soares et al. $(2000,2001)$ relatam uma idade de 630 a 585 Ma para os depósitos dessa fase tectônica.

Uma bacia do tipo foreland instalou-se nos domínios cratônicos, sob um regime tectônico flexural por sobrecarga (Martins-Neto et al. 1997, 2001, Castro \& Dardenne 2000, Martins-Neto \& Alkmim 2001), separada em alguns pontos mais centrais da bacia por uma discordância estimada em cerca de $150 \mathrm{Ma}$. Esses depósitos correspondem à Seqüência Bambuí (Fig. 3). Seus depósitos são constituídos, em sua grande maioria, por rochas carbonáticas e pelíticas (Dardenne 1978a, 1981, 2000). Arenitos (em parte turbiditos) e conglomerados também são descritos como pertencentes a essa seqüência, principalmente na porção mais a norte da área estudada (Martins-Neto 2005) e no sudoeste da bacia (Conglomerados Samburá, Castro \& Dardenne 2000). Registros bibliográficos indicam idades entre $740 \mathrm{e}$ 530 Ma para esses depósitos (Martins-Neto et al. 1997, 2001, Castro \& Dardenne 2000, Martins-Neto \& Alkmim 2001, Babinski \& Kaufman 2003).

\section{Tectônica modificadora e metamorfismo}

A Bacia do São Francisco na região estudada (Figs. 1, 2 e 3) apresenta uma compartimentação estrutural e metamórfica que espelha a sua evolução tectônica.

A Bacia do São Francisco pode ser dividida em três compartimentos (Fig. 1) (Alkmim et al. 1993, 1996, Alkmim \& Martins-Neto 2001): (i) um compartimento oeste, que corresponde à porção externa da Faixa Brasília, com vergência estrutural para leste; (ii) uma porção central onde as unidades neoproterozóicas da Seqüência Bambuí encontram-se praticamente indeformadas, e (iii) um compartimento leste, que corresponde à porção externa da Faixa Araçuaí, com vergência estrutural para oeste. Observa-se ainda que o grau de metamorfismo seja decrescente das faixas móveis adjacentes para a bacia, sendo que nos seus compartimentos oeste e central esse metamorfismo é inexistente, sendo de muito baixo grau no compartimento leste.

COMPARTIMENTO OESTE O compartimento oeste (Fig. 1), na área estudada, pode ser subdividido em duas porções, uma a norte, região de Cristalina-GO/Unaí/ Bonfinópolis de Minas, e outra a sul, região de Vazante/ Paracatu/João Pinheiro (Fig. 2).

$\mathrm{Na}$ porção sul, as rochas encontradas são predominantemente correspondentes à Seqüência Bambuí, as quais não apresentam metamorfismo. Na parte oeste dessa porção, encontramos rochas da Seqüência Vazante, as quais se mostram já afetadas por um metamorfismo de baixo grau, bem como da Seqüência Canastra/ Paranoá (região de Paracatu/MG), onde as rochas mostram um metamorfismo na fácies xisto-verde.

As principais estruturas observadas nessa região são dobras e falhas reversas (Dardenne 1978b, Bacellar 1989, Muzzi Magalhães 1989, Muzzi Magalhães et al. 1989), orientadas, preferencialmente segundo NNE-SSW e com vergência para leste (Alkmim \& Martins-Neto 2001). Observa-se ainda nessa porção, falhas transcorrentes, principalmente um feixe sinistral de direção N60W que afeta até o embasamento (Muzzi Magalhães 1989, Valeriano 1999). Segundo Muzzi Magalhães (1989), esse feixe de falhas teria se nucleado tardiamente no Evento Brasiliano, uma vez que afeta as dobras e falhas preexistentes.

$\mathrm{Na}$ porção norte, observa-se que as estruturas dominantes compõem um cinturão epidérmico de antepaís. Tais estruturas são dobras de vários tipos e dimensões, falhas reversas e transcorrências dextrais, todas elas relacionadas ao mesmo evento tectônico do Ciclo Brasiliano (Dardenne 1978b, Fonseca \& Dardenne 1993, Romeiro Silva et al. 1998, Alkmim \& MartinsNeto 2001, Martins-Neto 2005). As transcorrências têm orientação NE-SW, enquanto que as dobras e falhas mostram seus traços estruturais orientados, preferencialmente, segundo NNW-SSE com vergência para ENE (Alkmim \& Martins-Neto 2001).

As rochas encontradas nessa região pertencem, na sua maioria, à Seqüência Bambuí. A exemplo do ocorrido na porção sul, essas rochas não se encontram metamorfizadas. Entretanto, na parte proximal à faixa Brasília em Cristalina/GO, as rochas da Seqüência Canastra/Paranoá exibem um metamorfismo incipiente (Dardenne 1978b, Alkmim \& Martins-Neto 2001, Martins-Neto 2005, Coelho et al. 2005).

COMPARTIMENTO LESTE Assim como no compartimento oeste, o compartimento leste apresenta estruturas formando um cinturão de antepaís, nesse caso com a vergência para oeste (Fig. 3). As rochas envolvidas são as das seqüências Espinhaço, Canastra/Paranoá, Macaúbas e Bambuí (Alkmim \& Martins-Neto 2001, Martins-Neto 2005). O metamorfismo nesse compartimento é de incipiente a baixo grau, passando a de maior intensidade para leste, chegando a atingir condições de fácies xisto verde (Alkmim \& Martins-Neto 2001). Descreve-se como sendo característica principal desse compartimento a presença de uma clivagem de plano axial que fica mais intensa e penetrativa para leste (Marshak \& Alkmim 1989, Uhlein 1991, Oliveira 1994, Dussin \& Dussin 1995, Alkmim \& Martins-Neto 2001).

QUADRO EVOLUTIVO E ASPECTOS DA ÁREA ESTUDADA A Bacia do São Francisco, na região estudada, assim como foi definida por Alkmim \& Martins Neto (2001), pode ser compartimentada, tanto em 
superfície quanto em subsuperfície, seguindo critérios evolutivos e tectônicos.

O primeiro evento tectônico que atuou na formação da bacia, iniciado há cerca de 1300-1200 Ma nos domínios da Faixa Brasília e há cerca de 900 Ma nos domínios da Faixa Araçuaí (Dardenne 2000, Pimentel et al. 2000, Martins-Neto \& Alkmim 2001), foi um evento distensivo que fragmentou o Supercontinente Rodínia, provocando a abertura de dois riftes, que vieram a formar duas bacias do tipo rifte/margem passiva, uma a oeste, Canastra/Paranoá e outra a leste, Macaúbas (Brito Neves et al. 1993, Pedrosa-Soares \& WiedemannLeonardos 2000, Alkmim et al. 2001, Martins-Neto et al. 2001, Pedrosa-Soares et al. 2001). Na porção oeste da bacia, área de concentração deste trabalho, identificam-se na sísmica (Fig. 3), como representantes dessa fase, falhas normais de vergências opostas, características do processo distensivo. Como esses riftes sofreram posteriormente um processo de compressão, podem-se observar algumas dessas falhas normais invertidas para cavalgamentos (Fig. 4). Os dados sísmicos indicam também que parte das falhas reversas do evento compressional Brasiliano que envolvem o embasamento foram nucleadas a partir da reativação de falhas normais da fase rifte da bacia precursora.

Poder-se-ia especular que essa sucessão rifte reconhecida na sísmica (Figs. 3 e 4) seria relacionada ao processo de rifteamento do Estateriano, que, no caso da Faixa Brasília, deu origem à bacia Arai. Entretanto, se esse fosse o caso, teríamos o registro dessa unidade estratigráfica no cinturão de cavalgamentos da Faixa Brasília meridional, a oeste da bacia. Ao contrário, unidades estratigráficas de idade Estateriana (Arai ou Espinhaço) estão ausentes na Faixa Brasília meridional, onde ocorrem rochas pertencentes à Seqüência Canastra/Paranoá e correlatas.

Estruturas do tipo flor com direção SW-NE foram reconhecidas na sísmica (Figs. 3 e 5), permitindo interpretar que um evento de natureza transcorrente afetou os depósitos da Bacia do São Francisco em sua porção cratônica. $\mathrm{O}$ caráter positivo da maioria das estruturas-em-flor sugere que elas foram produtos de um evento transpressivo. $\mathrm{O}$ mapeamento sísmico mostra que essas estruturas possuem um trend SW-NE e deformam, sobretudo, a Seqüência Canastra/Paranoá, sendo responsáveis pelo desenvolvimento de uma proeminente discordância entre essa unidade e a Seqüência Bambuí (Fig. 6). Reativações posteriores dessas estru-
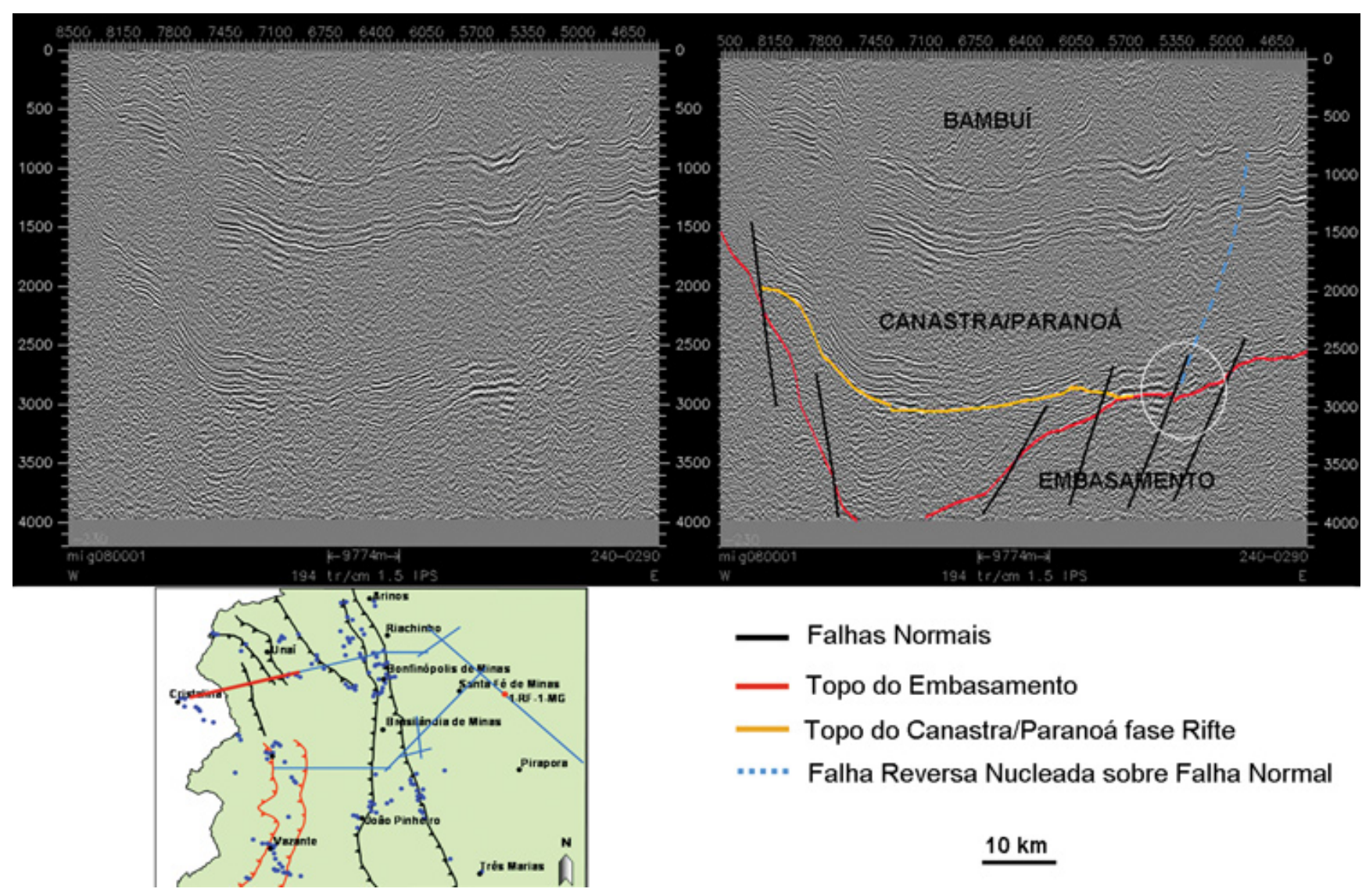

_ Falhas Normais

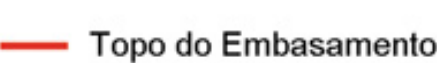

- Topo do Canastra/Paranoá fase Rifte

..... Falha Reversa Nucleada sobre Falha Normal

\section{$10 \mathrm{~km}$}

Figura 4 - Parte de uma linha sísmica em tempo na borda oeste da bacia rifte/margem passiva Canastra/Paranoá, mostrando as falhas normais. Notar no círculo inversão tectônica de falha normal gerando falha reversa que deforma a sucessão margem passiva da Seqüência Canastra/Paranoá, bem como o descolamento basal da tectônica epidérmica. 

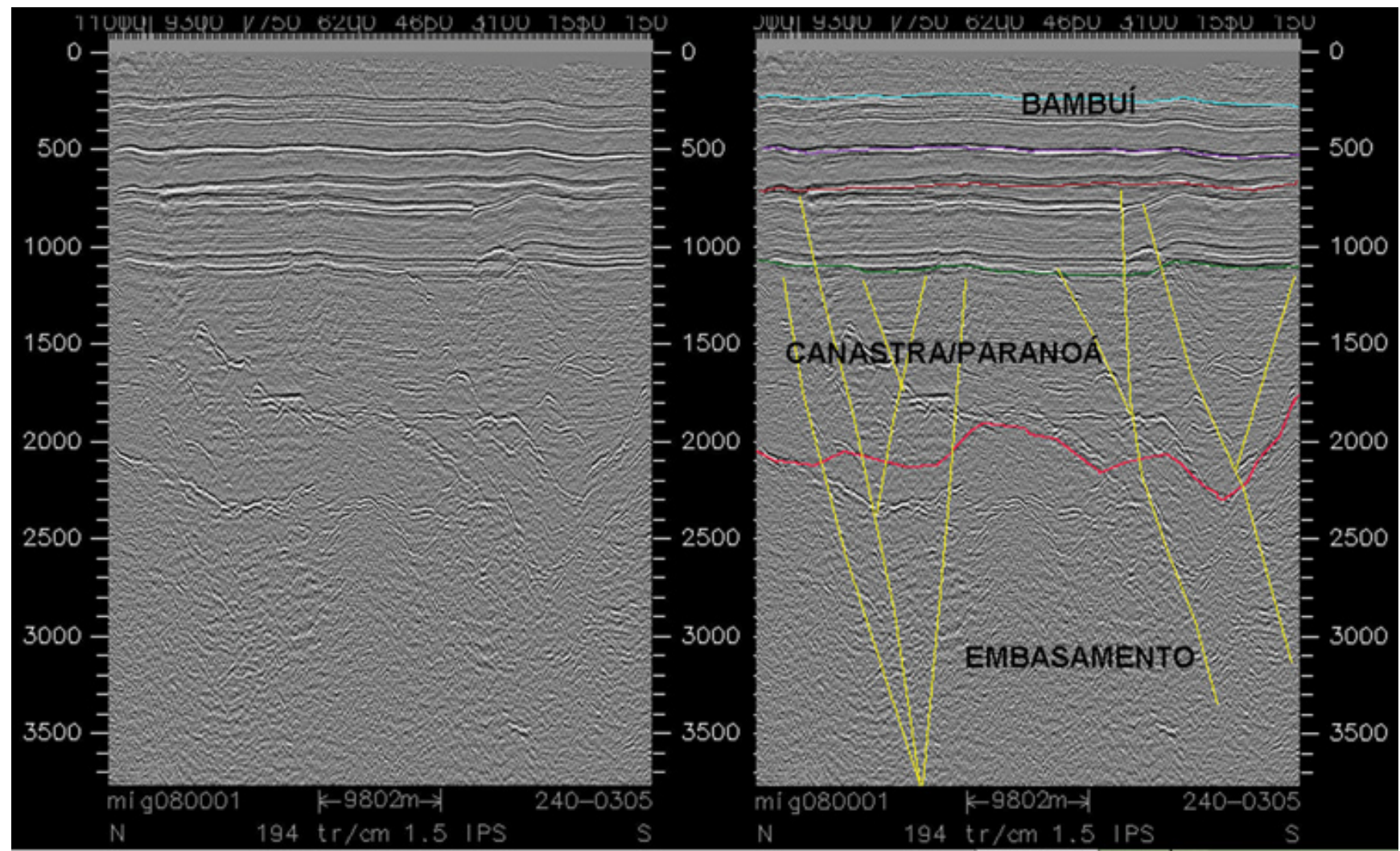

- Topo do Embasamento

- Topo Canastra/Paranoá Fase Margem Passiva Intermediário

- Topo Canastra/Paranoá Fase Margem Passiva Sup./ Base do Bambuí

- Topo do Bambuí inferior

- Topo do Bambuí Intermediário

- Falhas Transcorrentes

$10 \mathrm{~m}$

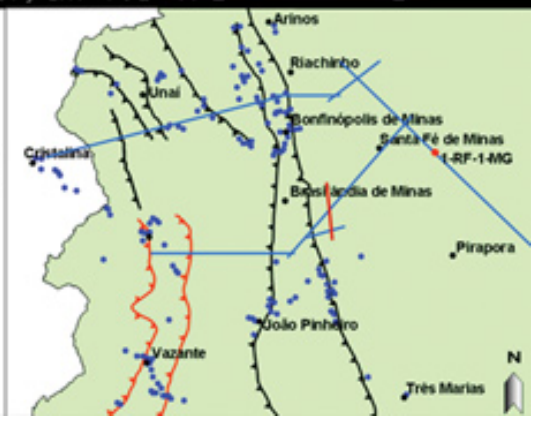

Figura 5 - Parte de uma linha sísmica em tempo na porção central da Bacia do São Francisco, mostrando estruturas-em-flor positivas decorrentes das transcorrências.

turas foram responsáveis localmente pela deformação da Seqüência Bambuí.

Não há elementos seguros para se precisar a idade dessa tectônica transcorrente, nem o seu contexto tectônico. Tendo em vista o fato da maioria das flores deformarem a Seqüência Canastra/Paranoá anteriormente à deposição da Seqüência Bambuí (Fig. 6), e a idade máxima dessa última, pode-se especular que o evento principal teria ocorrido por volta ou pouco antes de $740 \mathrm{Ma}$. A qualidade do dado sísmico não permite inferências seguras quanto ao início do processo, uma vez que feições sismoestratigráficas de sedimentação sintectônica não podem ser seguramente caracterizadas. Quanto ao contexto tectônico do evento transpressivo, pode-se especular que os esforços compressivos estariam relacionados ao início de processos acrescionários na margem continental.

As rochas sedimentares depositadas na bacia Canastra/Paranoá são predominantemente compostas por arenitos e pelitos com contribuição carbonática (Dardenne 1978a, 1981, 2000). Nas regiões da borda da bacia, onde parte desses depósitos da Seqüência Canastra/Paranoá encontra-se aflorante, pode-se comprovar que existem diferenças em termos de deformação e metamorfismo. Na região norte, próximo à cidade de Cristalina/GO, os depósitos marinho-rasos Canastra/ Paranoá encontram-se praticamente não deformados e metamorfizados (Fig. 7), enquanto que na região de Paracatu/MG, a deformação e metamorfismo são muito mais intensos, esse último chegando a condições de fácies xisto-verde (Fig. 8).

Essa diferença deformacional e metamórfica impressa nessas rochas está relacionada com a resposta local ao esforço compressional sofrido por elas, relacionado ao Ciclo Brasiliano (Dardenne 2000, Pimentel et al. 1999, 2000, Muzzi Magalhães 1989, Martins-Neto et al. 1997, 2001, Castro \& Dardenne 2000, MartinsNeto \& Alkmim 2001). 


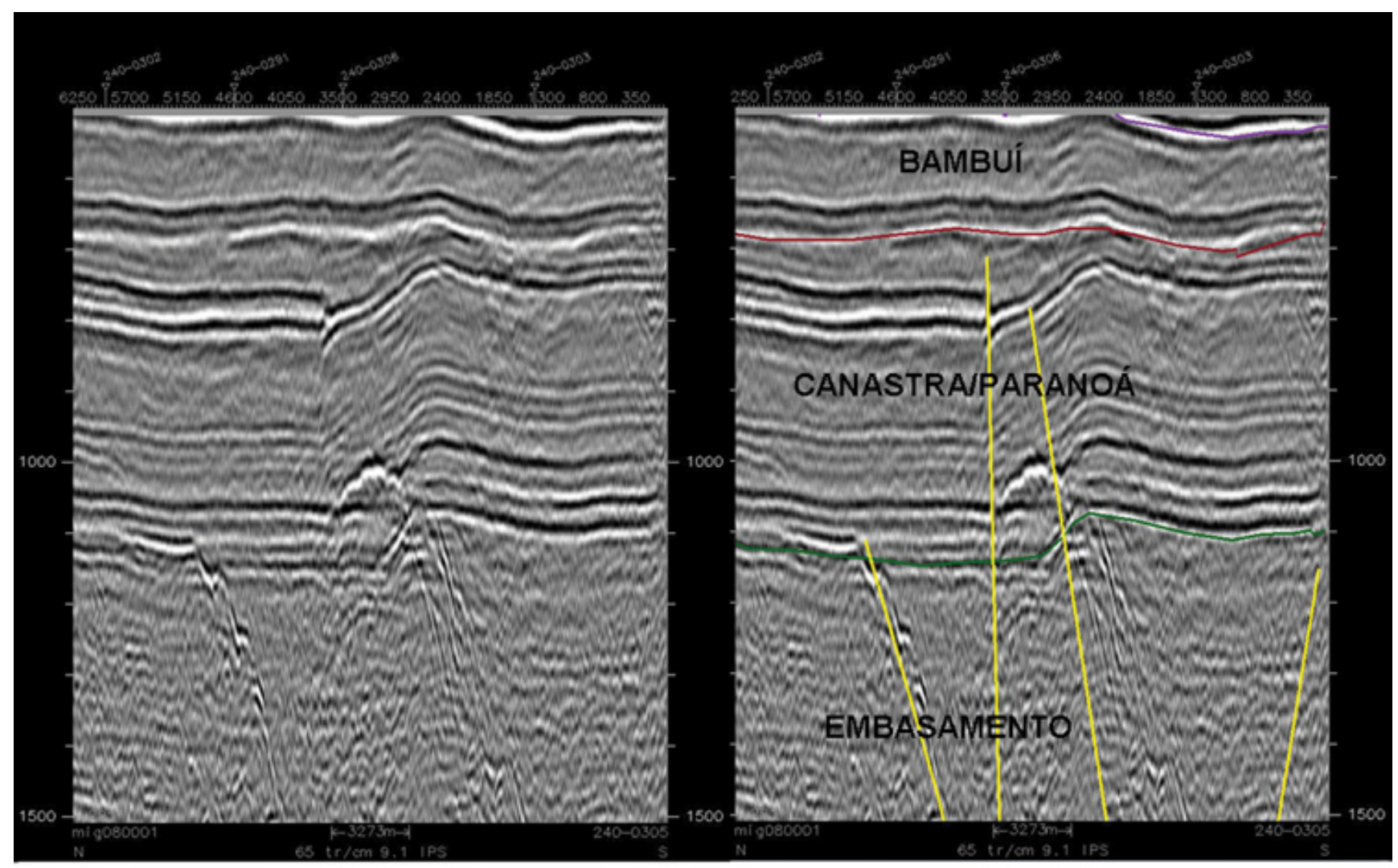

- Topo Canastra/Paranoá Fase Margem Passiva Intermediário

- Topo Canastra/Paranoá Fase Margem Passiva Superior e Base do Bambuí

- Topo do Bambui Inferior

- Falhas Transcorrentes

\section{$3 \mathrm{~km}$}

Figura 6 - Detalhe da linha sismica da figura anterior, mostrando a proeminente discordância entre as seqüencias Canastra/Paranoá e Bambui, produto da tectônica transcorrente, atestando que houve a exposição e erosão das camadas superiores da Seqüência Canastra/Paranoá antes da deposição da Seqüência Bambuí.

Esse esforço compressivo, que se propagou de oeste para leste, deu origem ao conjunto de dobras e falhas de empurrão com vergência para leste (Figs. 1, 3 e 9), que podem ser agrupadas em conjuntos relativos a duas fases deformacionais distintas: (i) uma mais antiga caracterizada por um cinturão epidérmico (thin-skinned) e (ii) uma posterior onde as falhas de empurrão envolvem o embasamento (thick-skinned), conforme detalhado a seguir.

A expressão mais antiga desse evento compressivo na borda oeste da Bacia do São Francisco é um cinturão epidérmico (thin-skinned) de antepaís (Figs. 1, $3,10,11$ e 12) (Alkmim \& Martins-Neto 2001, Martins-Neto 2005, Romeiro Silva \& Zalán 2005, Coelho et al. 2005), caracterizado por um descolamento basal, aflorante na região de Cristalina/GO, coincidente com a base da Seqüência Bambuí (Martins-Neto 2005, Coelho et al. 2005). A expressão aflorante do descolamento marca, nessa região, o limite oeste do cinturão epidérmico. O limite leste desse domínio, registrado pela falha mais distante da frente de empurrão, é a denomina- da falha de São Domingos (Fig. 10). A leste da falha de São Domingos observa-se, tanto em sísmica como em superfície, que as rochas da Seqüência Bambuí passam a ter um comportamento sub-horizontalizado, ou seja, sem deformação tectônica (Figs. 3, 10 e 13). Existe uma faixa externa dentro do cinturão epidérmico onde a distância maior entre as falhas proporciona a preservação de camadas da Seqüência Bambuí (Fig. 10). Essa região é mais extensa na parte sul, a leste de Paracatu/ MG (Coelho et al. 2005).

Os limites oeste e leste do cinturão epidérmico foram mapeados por meio da análise de imagem de SRTM combinado com satélite e de afloramentos, e da integração desses com a sísmica (Figs. 11 e 12).

Dentro do cinturão epidérmico, os depósitos sedimentares encontram-se fortemente deformados, dobrados e falhados, entretanto sem metamorfismo e com as estruturas primárias preservadas (Fig. 14).

Os estilos de deformação são diferentes para cada tipo reológico. Rochas mais competentes, como os arenitos e carbonatos, tendem a quebrar ao serem 


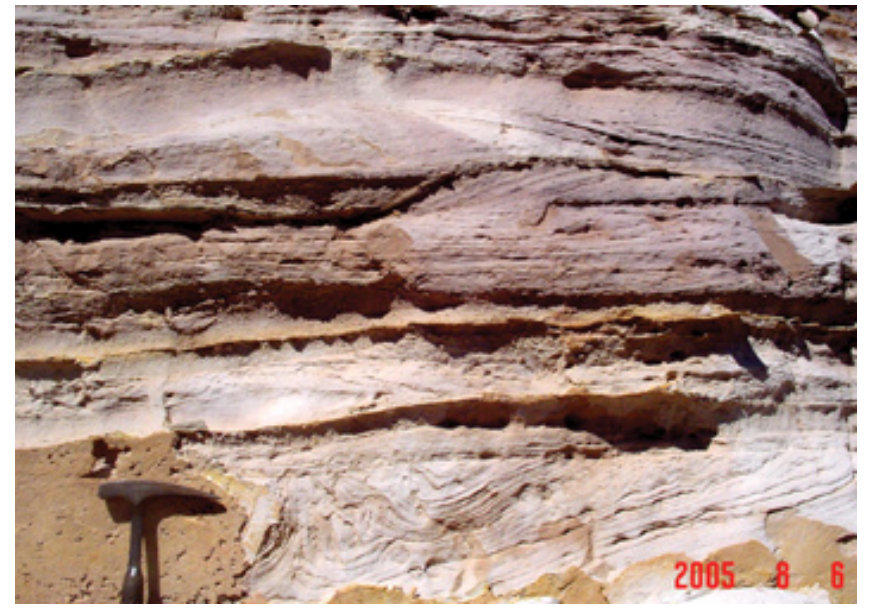

Figura 7 - Arenito Canastra/Paranoá nas imediações da cidade de Cristalina/GO. Notar ausência de deformação e preservação das estruturas sedimentares primárias como estratificações cruzadas e feições de fluidização. Afloramento BSF-JC-142 em uma pedreira na chegada de Cristalina/GO vindo de Unai/MG (GO-309 - estrada de terra).

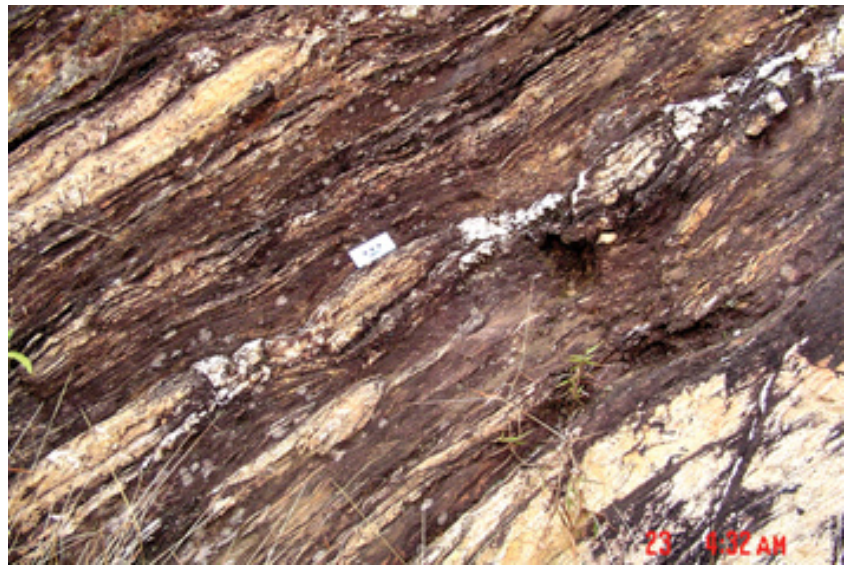

Figura 8 - Foto de arenito e pelito (Canastra/Paranoá). Notar que a deformação e o metamorfismo são bastante intensos quando comparados com a foto anterior. As camadas arenosas encontram-se boudinadas e às vezes rompidas pelo esforço tectônico. As camadas pelíticas encontram-se xistificada. Em ambas as camadas as estruturas sedimentares primárias foram completamente perdidas. Afloramento BSF-JC-118 às margens da MG188, próximo à cidade de Coromandel/MG.

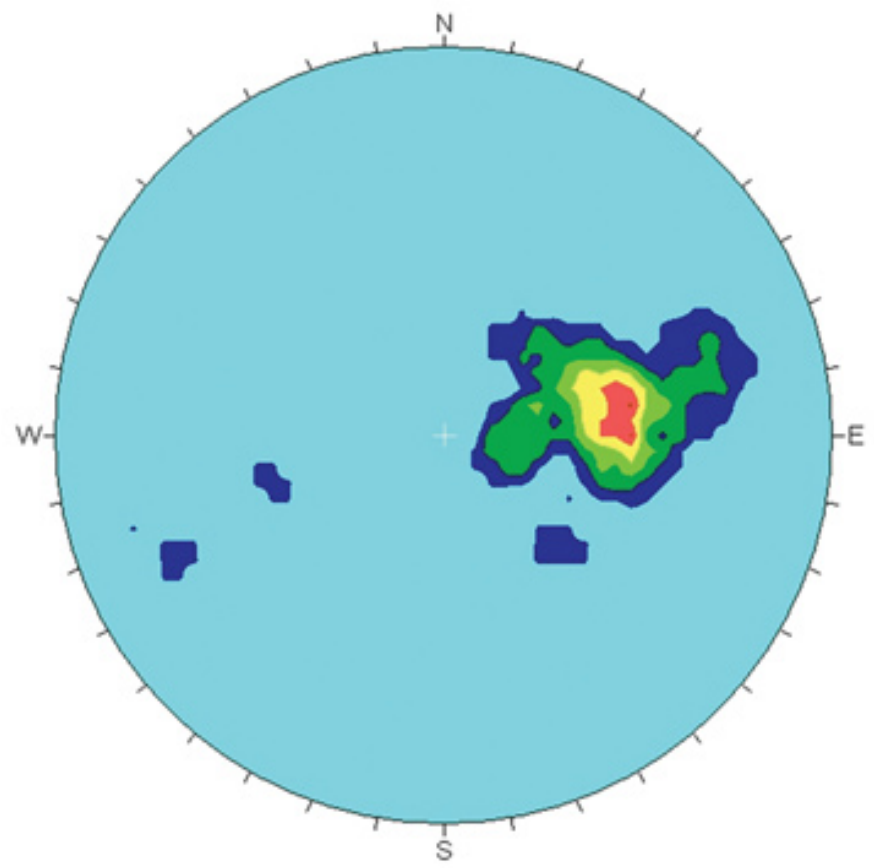

Schmidt

Concentrations

$\%$ of total per $1.0 \%$ area

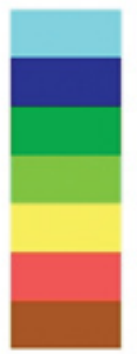

$0.00 \sim 3.50 \%$

$3.50 \sim 7.00 \%$

$7.00 \sim 10.50 \%$

$10.50 \sim 14.00 \%$

$14.00 \sim 17.50 \%$

$17.50 \sim 21.00 \%$

$21.00 \sim 24.50 \%$

No Bias Correction Max. Conc. $=21.5686 \%$

Equal Area

Lower Hemisphere

51 Poles

51 Entries

Figura 9 - Projeção estereográfica em diagrama de Schmidt (diagrama de pólos), mostrando atitude de falhas aflorantes, das fases thin e thick-skinned. Notar direção NS e vergência para leste.

deformados (Figs. 14 e 15), enquanto que rochas menos competentes, mais pelíticas, tendem a acomodar os esforços de maneira plástica (Fig. 16).

As falhas ocorrem na forma de leques imbrica- 


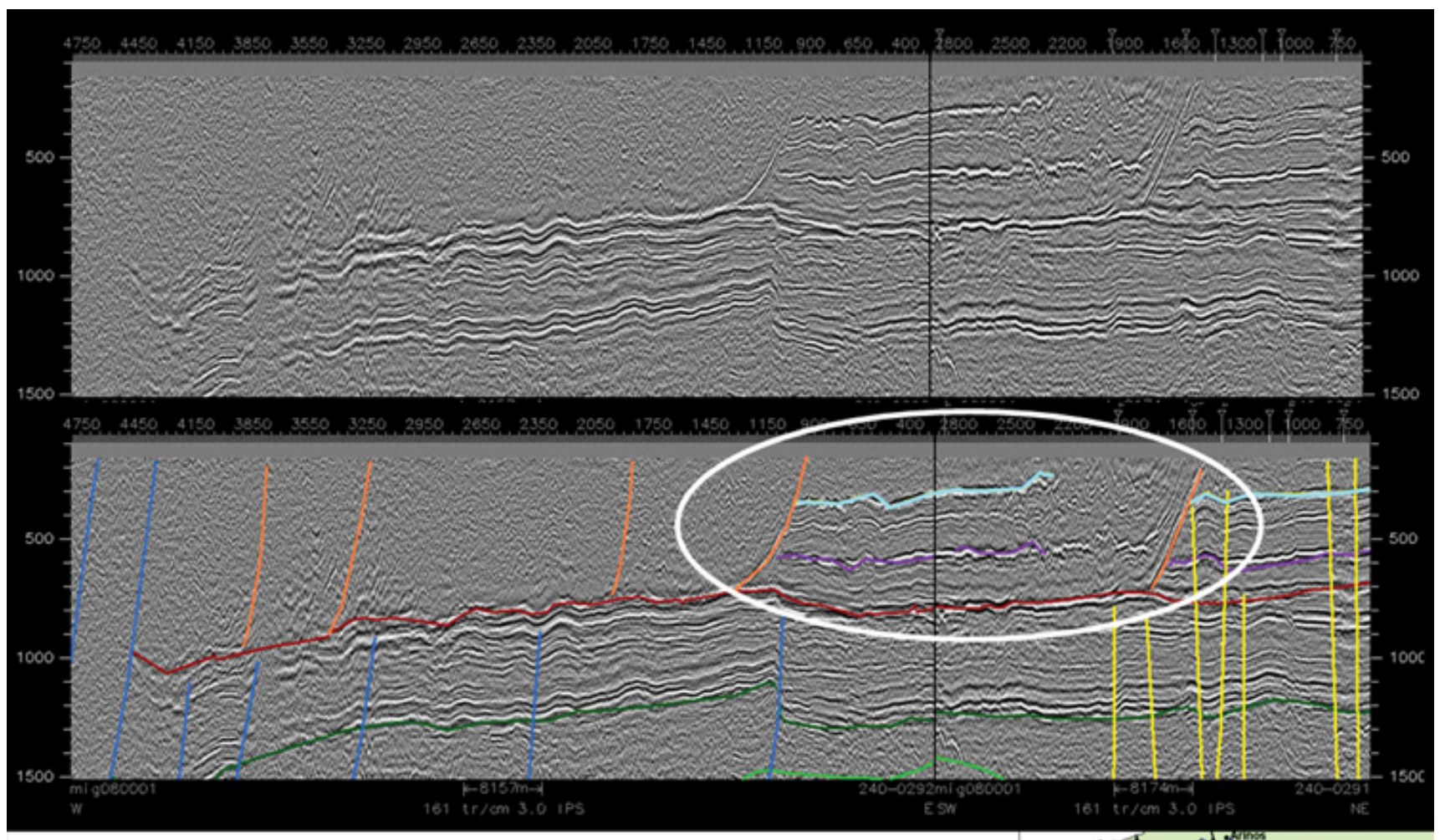

- Topo Canastra/Paranoá Fase Margem Passiva Inferior

- Topo Canastra/Paranoá Fase Margem Passiva Intermediário

- Topo Canastra/Paranoá Fase Margem Passiva Sup./ Base do Bambui

- Topo do Bambui Inferior

- Topo do Bambui Superior

- Falhas Reversas com Embasamento Envolvido

$8 \mathrm{~km}$

- Falhas Transcorrentes

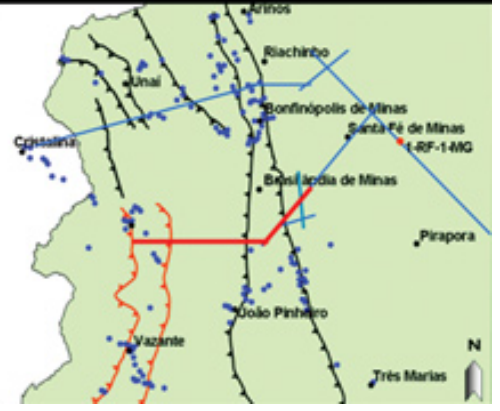

Figura 10 - Parte de uma linha sísmica em tempo na região oeste da Bacia do São Francisco mostrando, em linhas gerais, o comportamento do cinturão epidérmico, bem como seu descolamento basal, coincidente com a base da Seqüência Bambuí. A elipse mostra a região distal do leque imbricado, onde as maiores distâncias entre as falhas permitiram a preservação de camadas sub-horizontalizadas da Seqüência Bambuí.

dos, sendo observadas tanto em sísmica (Figs. 3 e 10) quanto em afloramento (Figs. 17, 18 e 19). Quando isto acontece, encontramos as camadas da Seqüência Bambuí mergulhando com altos ângulos. Também é comum nesses casos a zona de falha estar caracterizada por uma zona de deformação rúptil que pode atingir até cerca de $10 \mathrm{~m}$ de largura (Figs. 18 e 19). Nos domínios entre as falhas de empurrão, as camadas encontram-se muito dobradas e deformadas (Figs. 14, 15 e 16).

As falhas reversas da fase deformacional posterior com envolvimento do embasamento, thick-skinned, na porção mais externa da bacia, envolvem o embasamento e a coluna sedimentar, em parte como falhas cegas (blind thrusts), não rompendo em superfície (Fig. 20, região de Cristalina/GO), em parte rompendo na superfície (Fig. 21, região de Paracatu/MG). Muitas dessas falhas são nucleadas sobre as falhas normais do evento distensivo (Figs. 3, 4, 20 e 21). A diferença em termos de metamorfismo entre as regiões de Paracatu e
Cristalina, mencionadas anteriormente, são explicadas pelo rompimento em superfície das falhas que afetam o embasamento, na região de Paracatu, expondo rochas oriundas de níveis crustais mais profundos, pertencentes às seqüências Canastra/Paranoá e Vazante.

A tectônica de cavalgamento thin-skinned foi, conforme esperado tendo em vista outros exemplos bem estudados (p.ex., Cruz 2004, Cruz \& Alkmim 2005), anterior aos falhamentos da fase de embasamento envolvido, a julgar por critérios sísmicos que mostram esses últimos deformando ou mesmo rompendo o descolamento basal da tectônica thin-skinned (Fig. 22). Esse aspecto fica bem caracterizado na seção da figura 20 , onde as falhas envolvendo o embasamento (nesse caso cegas) soerguem o conjunto de rochas das seqüências Canastra/Paranoá e Bambuí, caracterizando o alto da cidade de Cristalina/GO como uma grande dobra de propagação de falha (fault-propagation fold), que envolve o descolamento basal do cinturão epidérmico 


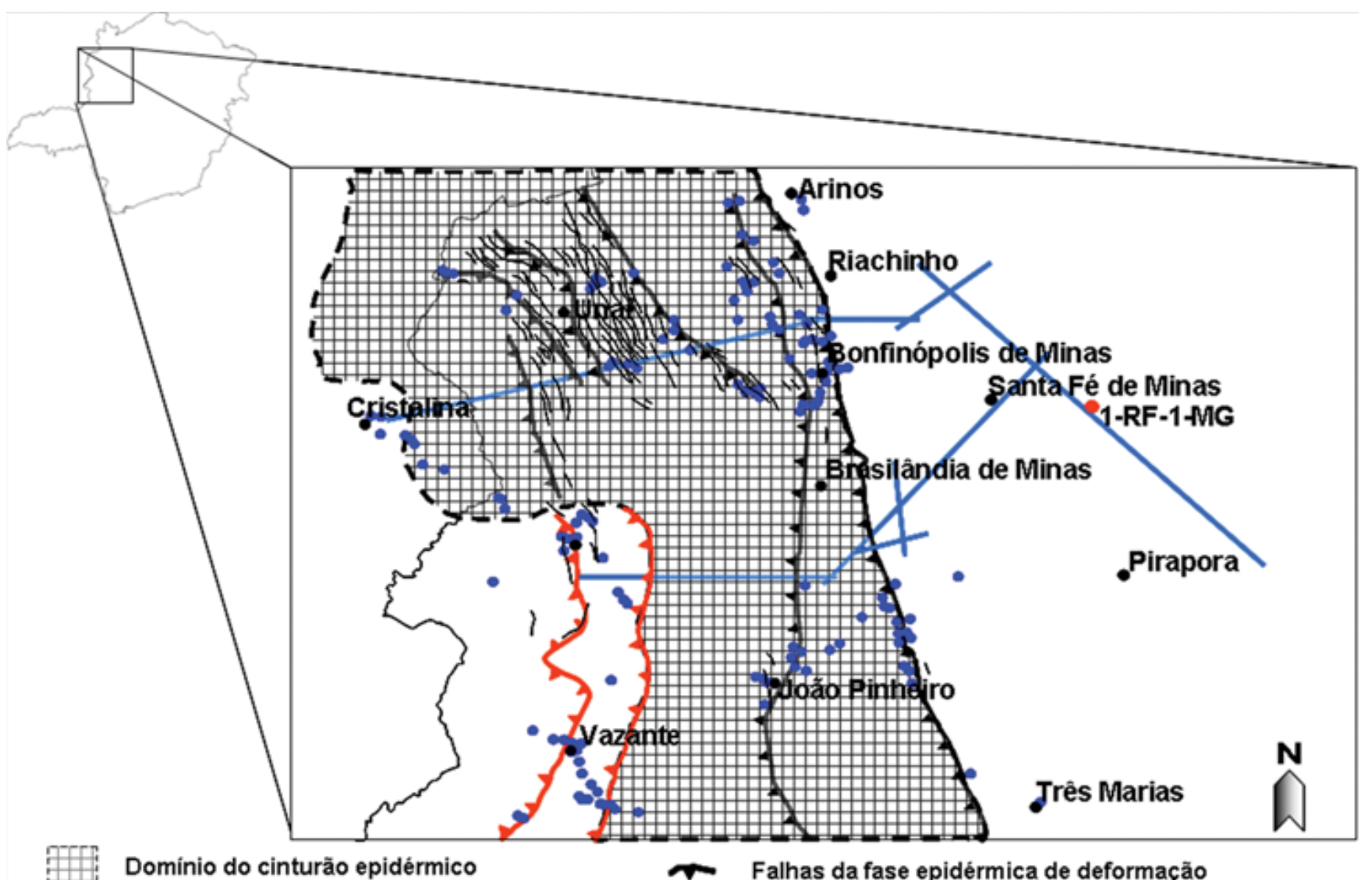

Limites inferidos elou detachment aflorante

Falhas da fase embasamento envolvido de deformação

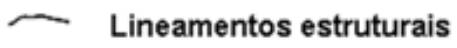

- Afloramentos visitados

Linhas sismicas estudadas

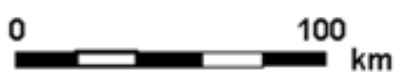

Figura 11 - Mapa da região estudada com parte dos afloramentos descritos e as principais estruturas identificadas. Observar a expressão do cinturão epidérmico na área estudada, cujos limites oeste e leste são normalmente representados por falhas reversas, exceto na região de Cristalina/GO, onde o limite é marcado pelo afloramento do descolamento basal (linha tracejada).

(Martins-Neto 2005).

Na borda leste da Bacia do São Francisco, região próxima a Serra da Água Fria, a sísmica nos mostra que a fase compressiva que afetou a região durante o Ciclo Brasiliano (Martins-Neto et al. 1997, 2001, Pedrosa-Soares et al. 2000, 2001, Alkmim \& MartinsNeto 2001) gerou um cinturão de antepaís com falhas reversas que envolvem toda a seção sedimentar até o embasamento (Fig. 23), em parte cegas como na cobertura da linha sísmica, em parte aflorantes como a sul da linha na região da Serra da Onça.

DISCUSSÕES E CONCLUSÕES Algumas conclusões puderam ser tiradas e/ou corroboradas por meio da execução deste trabalho:

Foram reconhecidos e caracterizados três grandes eventos tectônicos responsáveis pela formação e deformação das diversas etapas evolutivas da Bacia do São Francisco: (i) um evento distensional responsável pela formação de duas bacias do tipo rifte/margem passiva, uma a oeste (Canastra/Paranoá) e outra a leste (Macaúbas) dos domínios do Cráton do São Francisco, iniciado, respectivamente, a cerca de 1300-1200 Ma nos domínios da Faixa Brasília e a cerca de 900 Ma nos domínios da Faixa Araçuaí;

(ii) um evento transpressivo, responsável pelo desenvolvimento de flores positivas na porção cratônica da bacia, que afetam, sobretudo, a Seqüência Canastra/Paranoá e não a Seqüência Bambuí, desenvolvendo uma proeminente discordância entre essas unidades, e

(iii) um evento de natureza compressiva ligado ao Ciclo Brasiliano, responsável pela formação de uma bacia do tipo foreland sobre o Cráton do São Francisco (bacia Bambuí) e de dois cinturões de antepaís, o primeiro a oeste, com dobras e falhas reversas com vergência para leste chegando a envolver até o embasamento na borda da bacia e com um domínio thin-skinned. O 


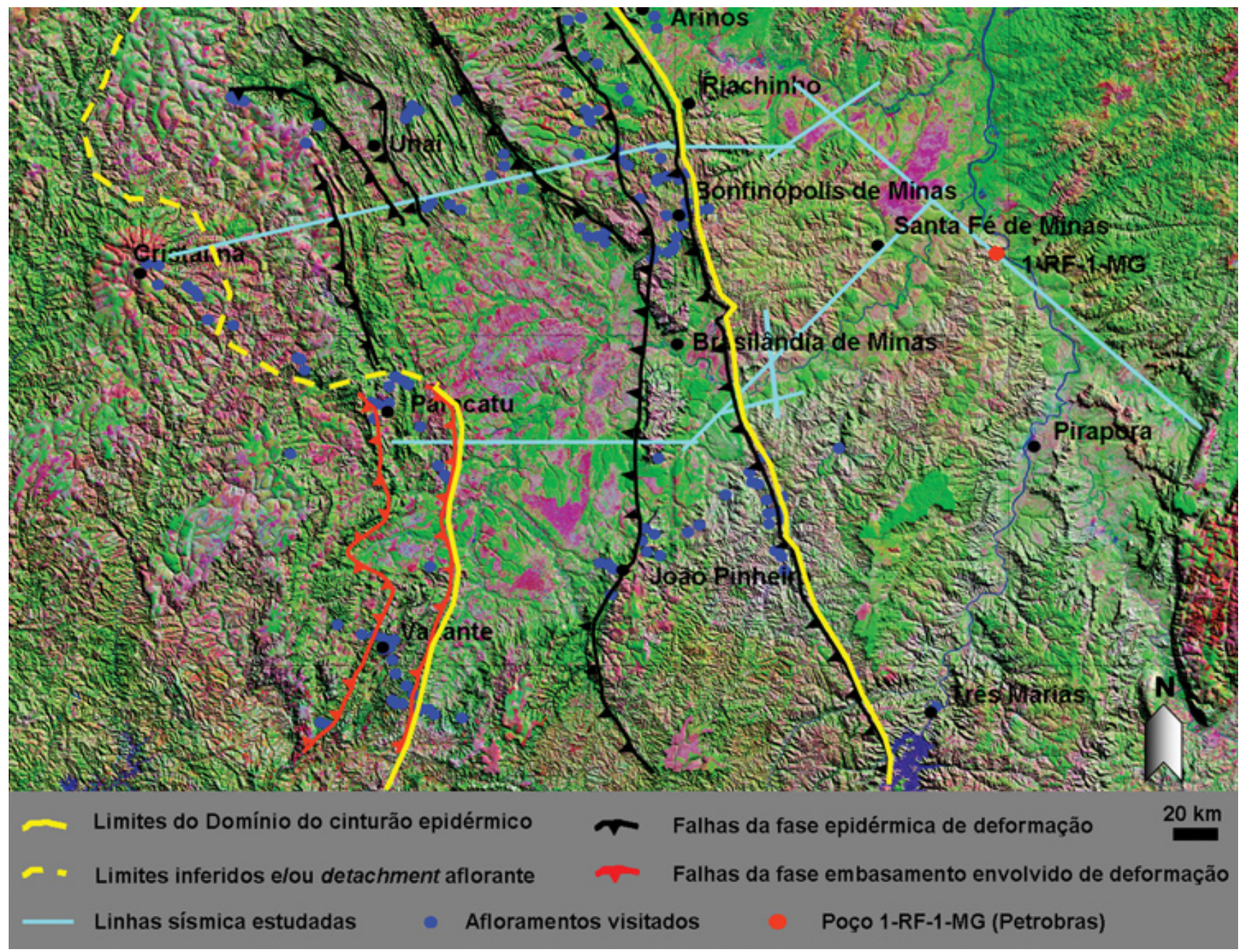

Figura 12 - Imagem de satélite mostrando os elementos estruturais do mapa da figura anterior, incluindo os limites do domínio epidérmico de deformação.

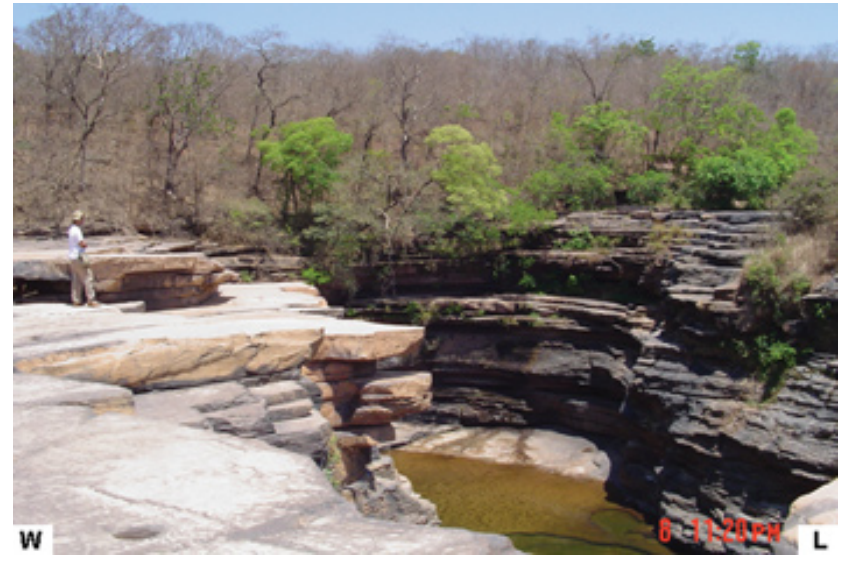

Figura 13 - Exemplo de afloramento do compartimento central da Bacia do São Francisco, sem deformação tectônica. Afloramento BSF-JC-105 sob a ponte sobre o rio do Sono na MG-408 que liga Brasilândia de Minas a Pirapora/MG, a cerca de $80 \mathrm{~km}$ de Brasilândia.

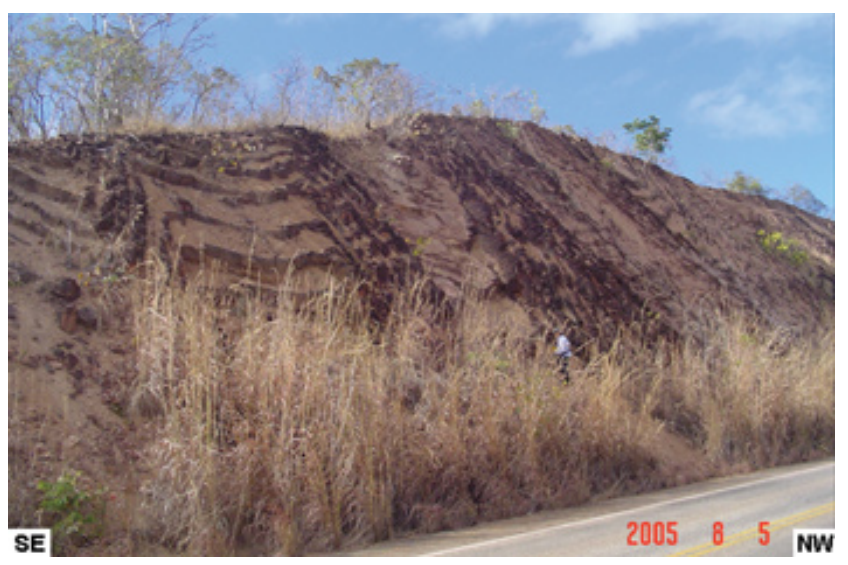

Figura 14 - Exemplo de afloramento com as rochas do cinturão epidérmico bastante deformadas. As estruturas sedimentares primárias encontram-se preservadas. Afloramento BSF-JC-30 em corte de estrada na BR-25I que liga Unaí/MG a Brasília/DF próximo ao km 902. 


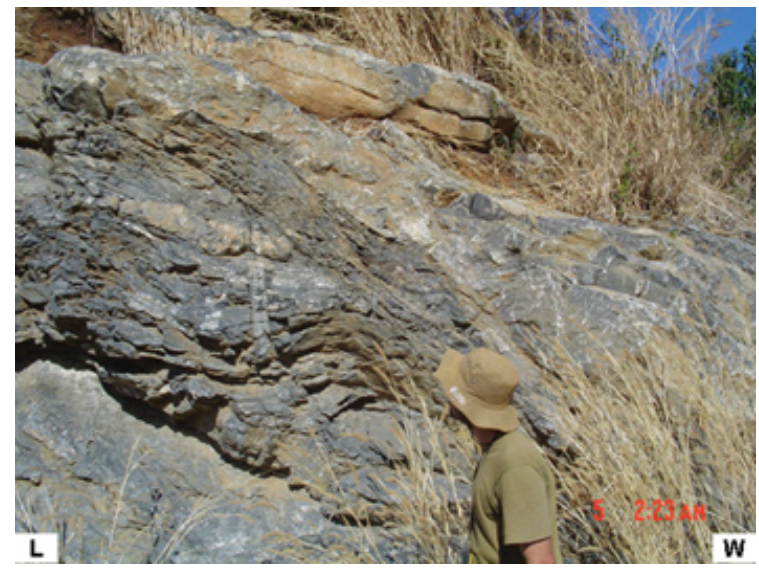

Figura 15 - Exemplo de afloramento com as rochas do cinturão epidérmico mostrando rocha carbonática deformada pelo empurrão. Afloramento BSFJC-33 em pedreira carbonática junto à barragem do Boqueirão, nas proximidades de Unaí/MG.

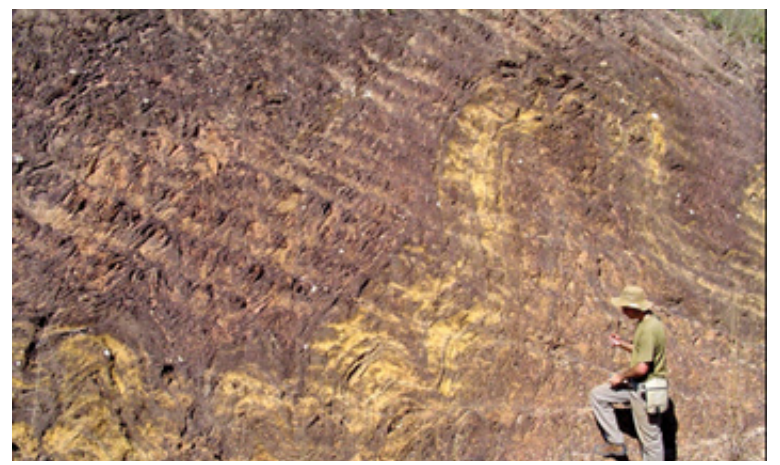

Figura 16 - Exemplo de afloramento com as rochas do cinturão epidérmico evidenciando a deformação plástica observada nas rochas pelíticas (camada guia em amarelo). Afloramento BSF-JC-35 em corte de estrada na MG-202 que liga Unai/MG a Arinos/ $M G$ a cerca de $13 \mathrm{~km}$ do trevo na saída de Unaí.

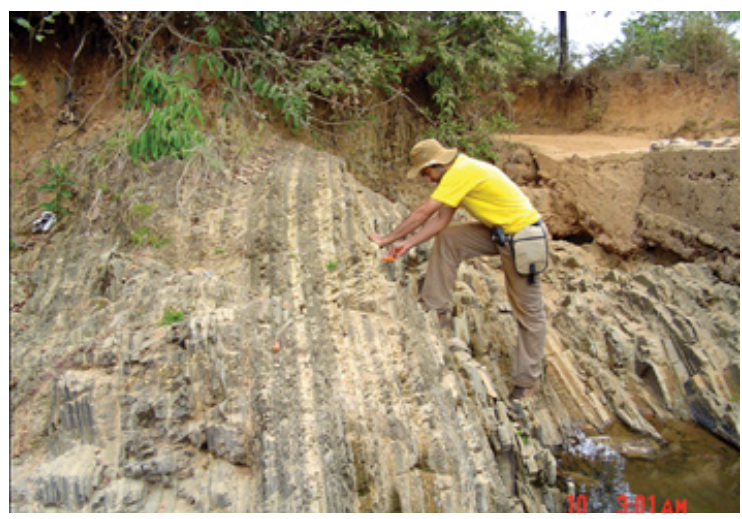

Figura 17 - Exemplo de afloramento com as rochas do cinturão epidérmico em zona de falha, onde se podem observar as camadas sub-verticalizadas $\left(S_{0}=252 / 90\right)$. Afloramento BSF-JC-73 em drenagem do ribeirão Canabrava em estrada secundária próxima a Canabrava (distrito de João Pinheiro/MG).

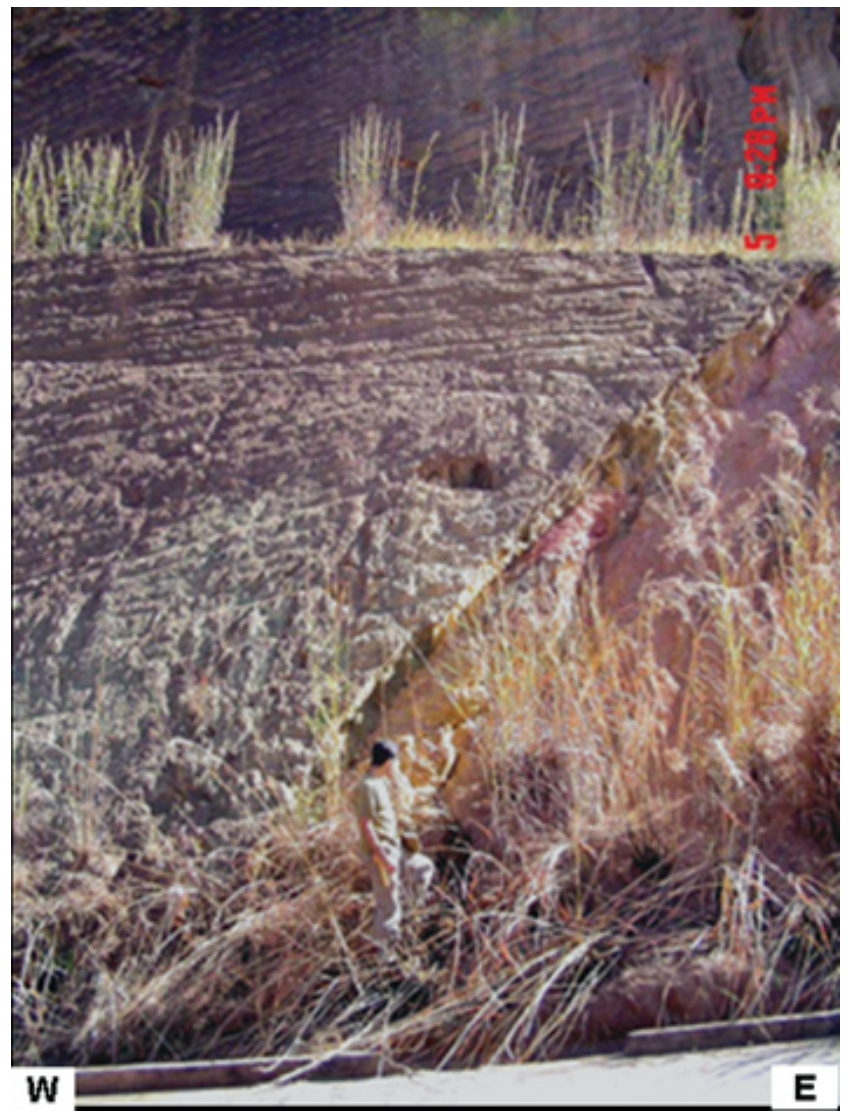

Figura 18 - Exemplo de afloramento de falha reversa do cinturão epidérmico, onde se observam rochas areno-peliticas na capa e rochas silto-argilosas na lapa. Afloramento BSF-JC-34 em corte de estrada MG-202 que liga Unaí/MG a Arinos $/ M G$ a cerca de $3 \mathrm{~km}$ do trevo na saída de Unaí.

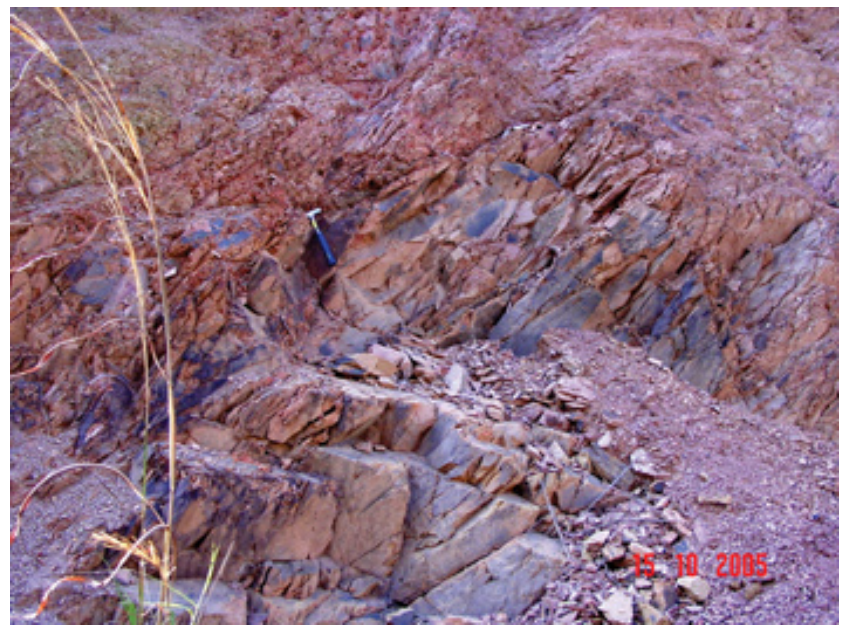

Figura 19 - Detalhe da foto anterior mostrando a deformação rúptil associada à zona de falha. 


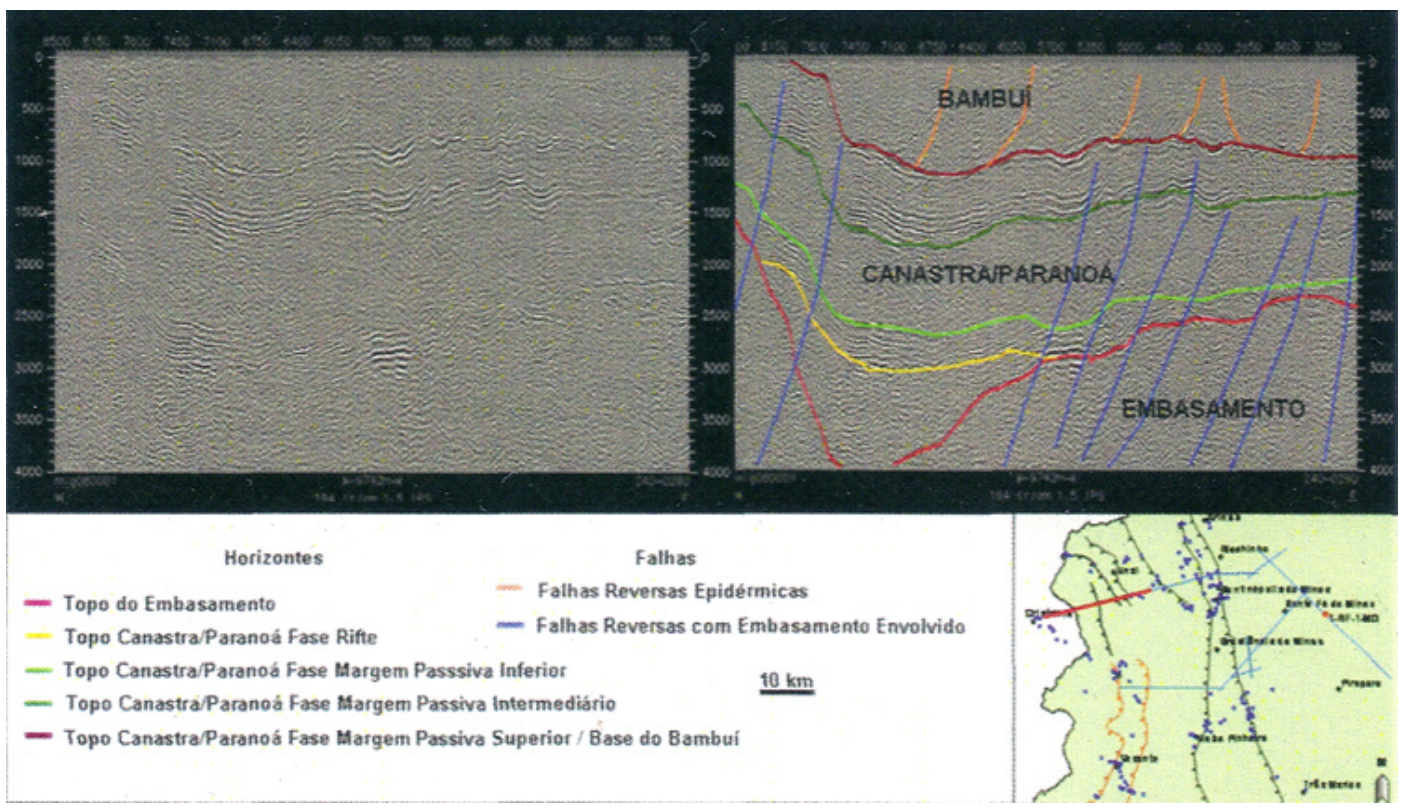

Figura 20 - Parte de uma linha sísmica em tempo na borda oeste da Bacia do São Francisco, na região de Cristalina/GO, mostrando as falhas de empurrão com vergência para leste envolvendo o embasamento. Ressalta-se aqui que essas são falhas cegas, nessa região.

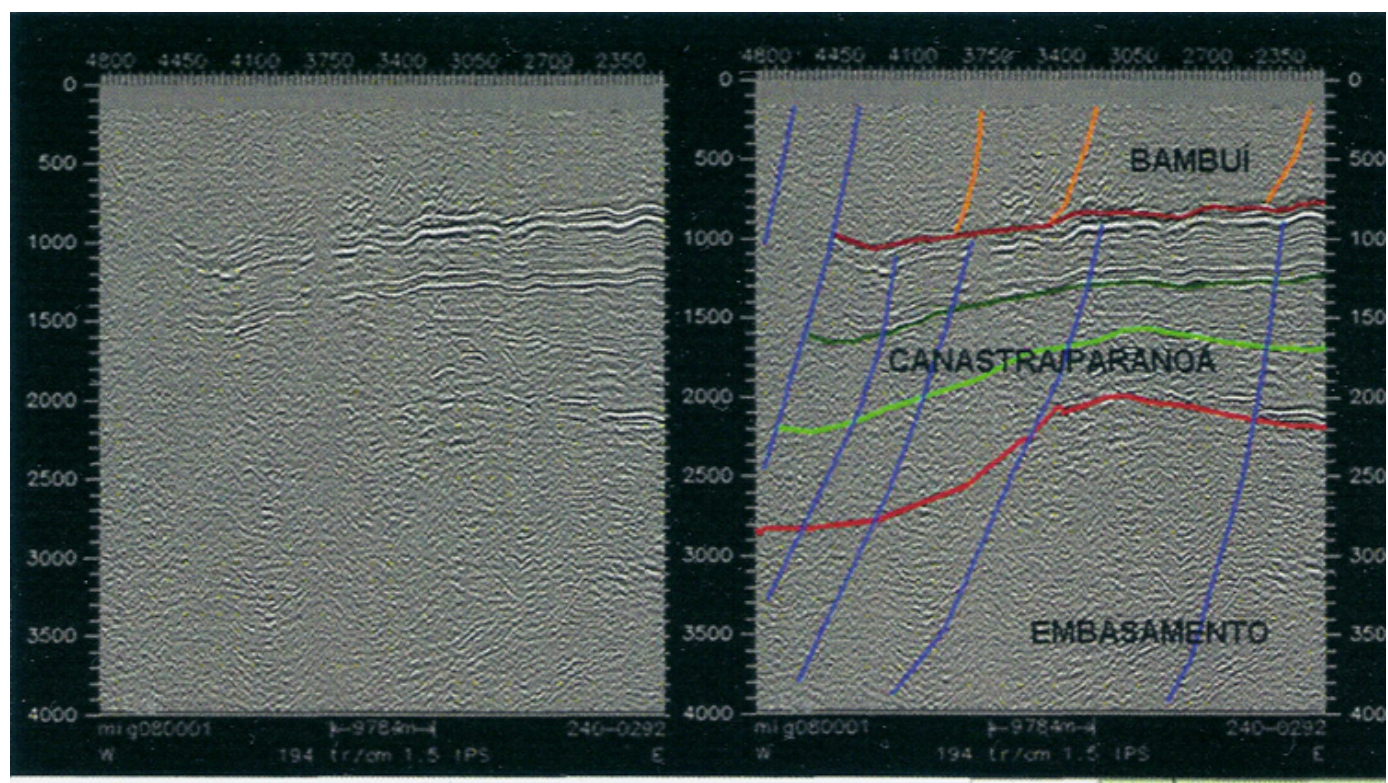

Horizontes

- Topo do Embasamento

- Topo Canastra/Paranoá Fase Rifte

- Topo Canastra/Paranoá Fase Margem Passsiva Inferior

- Topo Canastra/Paranoá Fase Margem Passiva Intermediário

- Topo Canastra/Paranoá Fase Margem Passiva Superior / Base do Bambuí

\section{Falhas}

- Falhas Reversas Epidérmicas

- Falhas Reversas com Embasamento Envolvido

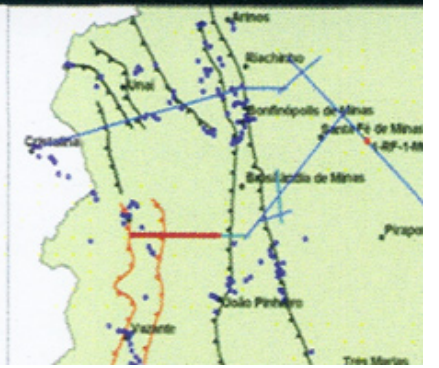

Figura 21 - Parte de uma linha sísmica em tempo na borda oeste Bacia do São Francisco, na região de Paracatu/MG, mostrando as falhas de empurrão envolvendo o embasamento aflorando na extremidade oeste da linha. A primeira falha a oeste, aflorante na região do Morro do Ouro, coloca rochas da Seqüência Canastra/Paranoá sobre rochas da Seqüência Vazante, enquanto a segunda coloca essas rochas sobre depósitos da Seqüência Bambuí, essas sem nenhum metamorfismo. 


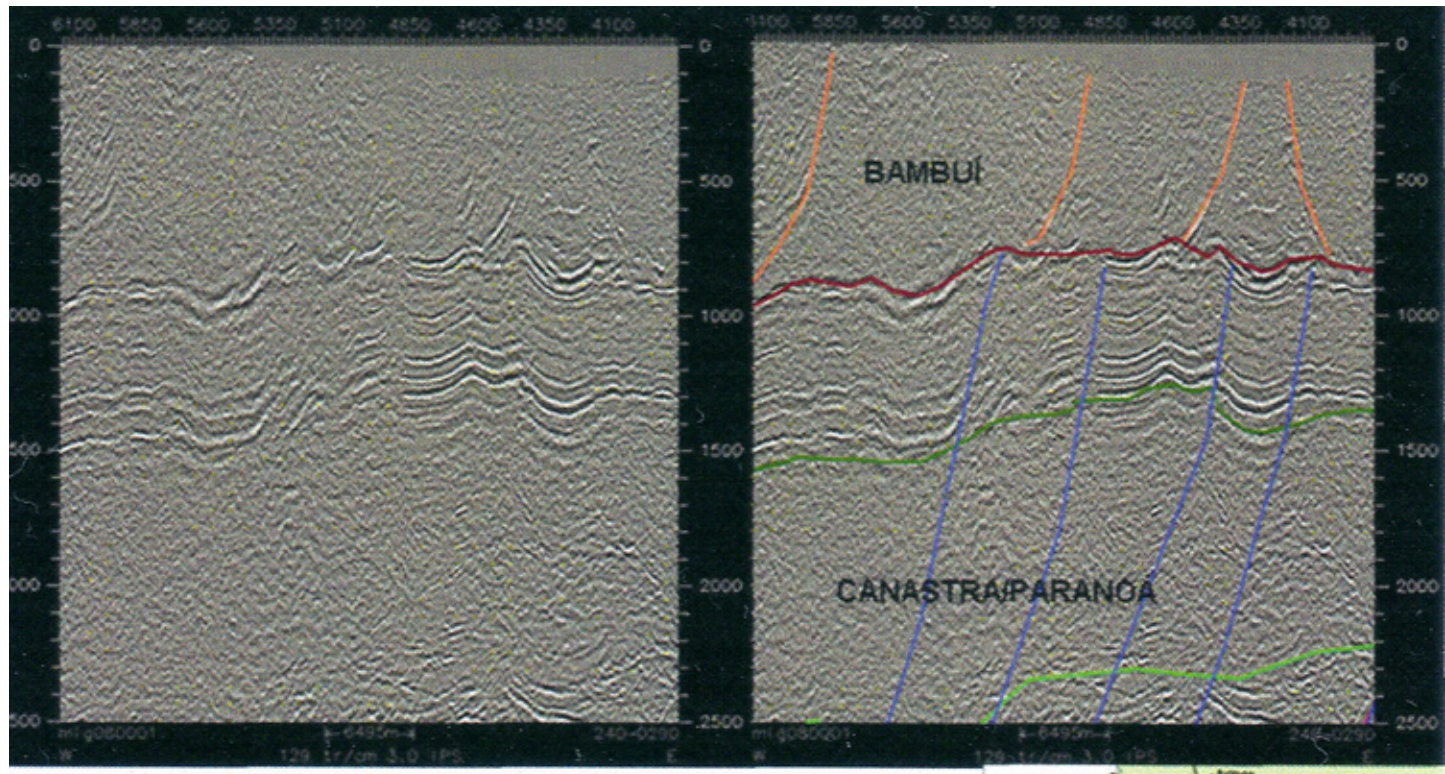

Horizontes

- Topo Canastra/Paranoá Fase Margem Passsiva Inferior

- Topo Canastra/Paranoá Fase Margem Passiva Intermediário

- Topo Canastra/Paranoá Fase Margem Passiva Superior / Base do Bambui

$$
\text { Falhas }
$$

- Falhas Reversas Epidérmicas

$\underline{6 \mathrm{~km}}$

- Falhas Reversas com Embasamento Envolvido

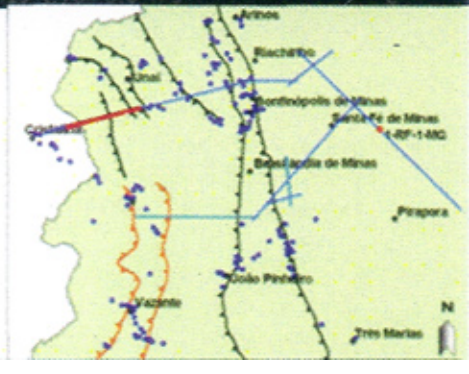

Figura 22 - Parte de uma linha sísmica em tempo próxima à borda oeste Bacia do São Francisco, mostrando as falhas reversas da fase embasamento envolvido deformando o descolamento basal da fase epidérmica de deformação e, assim, confirmando a cronologia desses eventos.

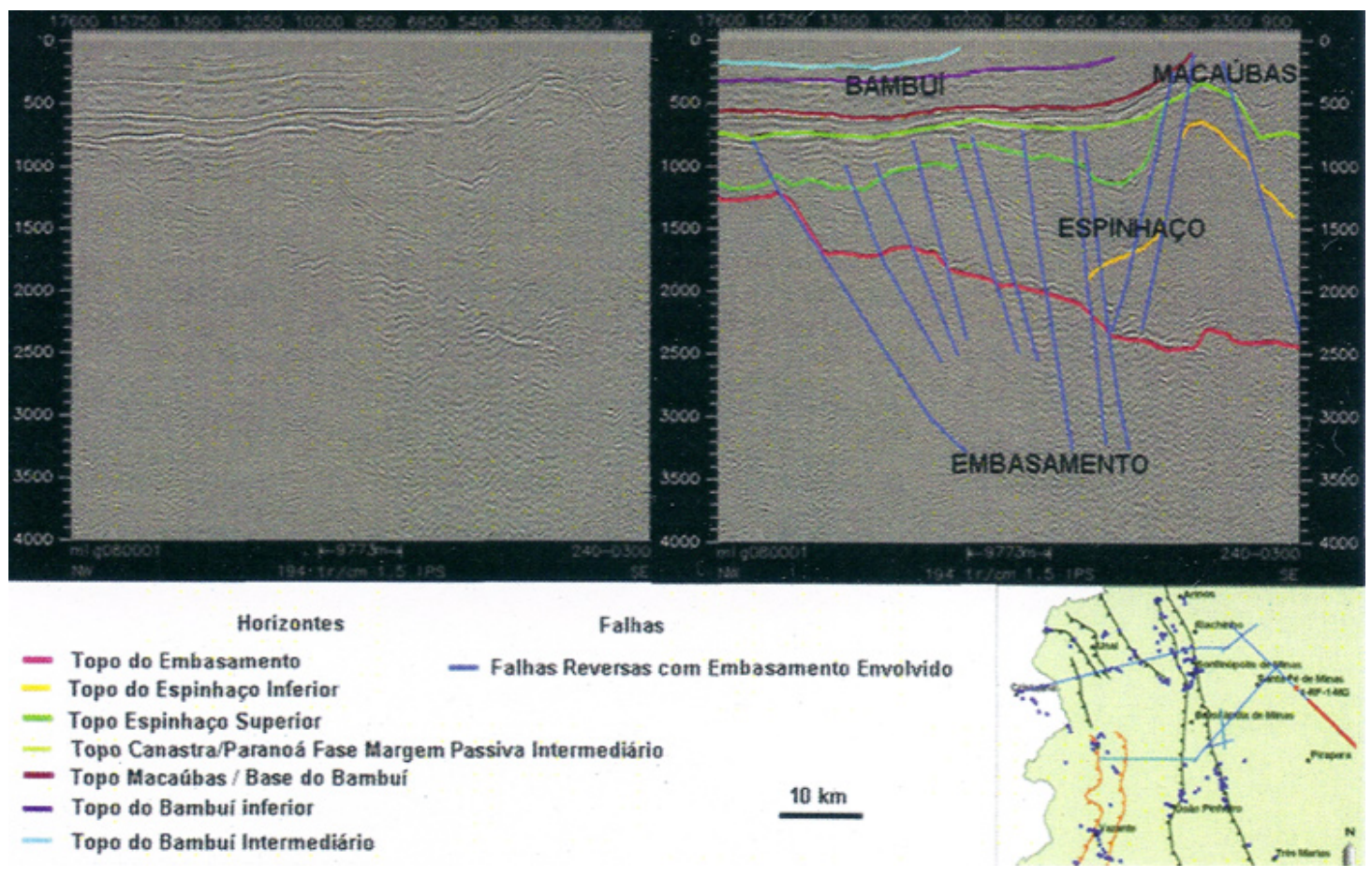

Figura 23 - Parte de uma linha sísmica em tempo próxima à borda leste Bacia do São Francisco, na região da Serra da Água Fria, mostrando as falhas reversas cegas com vergência para oeste e que envolvem o embasamento. 
segundo, a leste, com as dobras e falhas de empurrão com vergência para oeste.

Diante do exposto, algumas questões permanecem em aberto:

1 - O ponto onde a falha de empurrão da fase envolvendo o embasamento que aflora na região de Paracatu/MG torna-se cega para norte em direção a Cristalina/GO (Figs. 11 e 12) não pôde ser mapeado no campo e não foi contemplado pela sísmica. Trabalhos de campo de detalhe são necessários no sentido de mapear essa feição.

2 - Alguns raros afloramentos sugerem a contribuição das transcorrências, mapeadas na sísmica e mencionadas, dentre outros, por Muzzi Magalhães (1989) e por Alkmim \& Martins-Neto (2001), na construção geométrica das estruturas observadas. Entretanto, por se tratar de um trabalho regional, a escala do mapeamento de campo não nos permitiu concluir a esse respeito.

3 - É de suma importância no entendimento da evolução da Bacia do São Francisco, que estudos litogeoquímicos e geocronológicos sejam levados a cabo para uma melhor amarração do contexto geotectônico e idades deposicionais das diferentes unidades da bacia.

Agradecimentos À PETROBRAS pela liberação do primeiro autor para dedicação a projeto de mestrado e pela cessão da imagem de satélite da área, fornecida pelo Geólogo J.B.L. Françolin. Ao CNPq por concessão de Bolsa de Produtividade em Pesquisa a MAMN, vinculada ao projeto. À ANP pela cessão dos dados para fins acadêmicos. À Landmark pela cessão do pacote de softwares para fins acadêmicos. À Ufop e a Capes pelo aluno bolsista do PET Marcelo de Souza Marinho para se dedicar a este projeto. Aos revisores da RBG pelas valiosas contribuições. Finalmente, à interação universidade-indústria (em especial devida à Ufop, Fundação Gorceix e Petrobras) que possibilita um saudável e prolífero intercâmbio de experiências.

\section{Referências}

Alkmim F.F., Brito Neves B.B. \& Castro Alves J.A. 1993. Arcabouço tectônico do Cráton do São Francisco - Uma revisão. In: J.M.L. Dominguez \& A. Misi (eds.) O Cráton do São Francisco, SBG/Núcleo BA/SE, pp.: 45-62.

Alkmim F.F., Chemale Jr.F. \& Endo I. 1996. A deformação das coberturas proterozóicas do Cráton do São Francisco e o seu significado tectônico. Rev. Esc. Minas, 49(1): 22-38.

Alkmim F.F. \& Marshak S. 1998. Transamazonian orogeny in the southern São Francisco craton region, Minas Gerais, Brazil: evidence for Paleoproterozoic Collision and collapse in the Quadrilátero Ferrífero. Precambrian Res., 90: $29-58$.

Alkmim F.F., Marshak S. \& Fonseca M.A. 2001. Assembing West Gondwana in the Neoproterozoic: Clues from the São Francisco cratonregion, Brazil. Geology, 29: 319-322.

Alkmim F.F. \& Martins-Neto M.A. 2001. A Bacia intracratônica do São Francisco: arcabouço estrutural e cenários evolutivos. In: C.P. Pinto \& M.A. Martins-Neto (eds.) Bacia do São Francisco: Geologia e Recursos Naturais, SBG/Núcleo MG, pp.: 9-30.

Babinski M. \& Kaufman A.J. 2003. First direct dating of a Neoproterozoic post-glacial cap carbonate. In: South American Symposium on Isotope Geology, 4, Salvador, Short Papers, v.1. p. 321-323.

Bacellar L.A.P. 1989. Geologia estrutural do Supergrupo São Francisco ao longo da seção regional Coromandel-Três Marias-Conselheiro Mata, MG. Dissertação de Mestrado, Departamento de Geologia da Escola de Minas, Universidade Federal de Ouro Preto, 128 p.

Brito Neves B.B., Sá J.M., Nilson A.A. \& Botelho N.F. 1996. A tafrogênese estateriana nos blocos paleoproterozóicos da América do Sul e processos subseqüentes. Geonomos, 3: $1-21$

Brito Neves B.B., Van Schmus W.R. \& Babinski M, Sabin
T. 1993. O evento de magmatismo de 1,0 Ga nas faixas móveis ao norte do Cráton do São Francisco. In: SBG, Simp. do Cráton do São Francisco, 2, Salvador, Anais, p. 243-245.

Castro P.T.A. \& Dardenne M.A. 2000. The sedimentology, stratigraphy and tectonic context of the São Francisco Supergroup at the southern boundary of the São Francisco craton, Brazil. Rev. Bras. Geoc., 30: 345-437.

Coelho J.C.C, Martins-Neto M.A. \& Marinho M.S. 2005. Delimitação da província alóctone da fase thin-skinned de deformação na borda oeste da Bacia do São Francisco. In: SBG, Simp. Craton São Francisco, 3, Salvador, Anais, p. 208-210.

Cruz S.C.P. 2004. A interação tectônica entre o Aulacógeno do Paramirim e o Orógeno Araçuaí-Oeste Congo. Tese de Doutorado, Departamento de Geologia, Universidade Federal de Ouro Preto, 503 p.

Cruz S.C.P. \& Alkmim F.F. 2005. A interação tectônica entre o Aulacógeno do Paramirim e o Orógeno Araçuaí-Oeste Congo. In: SBG, Simp. Craton São Francisco, 3, Salvador, Anais, p. 215-218.

Dardenne M.A. 1978a. Síntese sobre a estratigrafia do Grupo Bambuí no Brasil Central. In: SBG, Congr. Bras. Geol., 30, Recife, Anais, v.2, p. 507-610.

Dardenne M.A. 1978b. Zonação tectônica na borda ocidental do Cráton do São Francisco. In: SBG, Congr. Bras. Geol. 30, Recife, Anais, v.1, p. 299-308.

Dardenne M.A. 1981. Os grupos Paranoá e Canastra na faixa dobrada Brasília. . In: SBG, Simp. Craton São Francisco, Anais, v.1, p. 104-157.

Dardenne M.A. 2000. The Brasília fold belt. In: U.G. Cordani, E.J. Milani, A. Thomaz Fo \& D.A. Campos (eds.) Tectônic Evolution of South America. Rio de Janeiro, pp.: 231-263. (Intern. Geol. Congr.,31).

Dussin I.A. \& Dussin T.M. 1995. Supergrupo Espinhaço: modelo de evolução geodinâmica. Geonomos, 3(1): 19-26. 
Fonseca M.A. \& Dardenne M.A. 1993. Sistemas de falhamentos transcorrentes na porção norte da Faixa de Dobramentos Brasília. In: SBG/BA-SE, SGM/BA, Simp. Cráton do São Francisco, 2, Salvador, Anais, p. 280-282.

Fugita A.M. \& Clark Fo.J.G. 2001. Recursos energéticos da Bacia do São Francisco: Hidrocarbonetos líquidos e gasosos. In: P.P. Claiton \& M.A. Martins-Neto (eds.) Bacia do São Francisco: Geologia e Recursos Naturais, SBG/ Núcleo MG, pp.: 265-284.

Marshak S. \& Alkmim F.F. 1989. Proterozoic contraction/ extension tectonics of the southern São Francisco region, Minas Gerais, Brazil. Tectonics, 8(3): 555-571.

Martins-Neto M.A., Castro P.T.A. \& Hercos C.M. 1997. O Supergrupo São Francisco (Neoproterozóico) no Cráton do São Francisco em Minas Gerais. Bol. $S B G / M G, 14$ : 22-24.

Martins-Neto M.A. 1998. O Supergrupo Espinhaço em Minas Gerais: registro de uma bacia rifte-sag do Paleo/Mesoproterozóico. Rev. Bras. Geoc., 28: 151-168.

Martins-Neto M.A. 2000. Tectonics and sedimentation in the Paleo/Mesoproterozoic rift-sag basin (Espinhaço Basin, sutheastern Brazil). Precambrian Res., 103: 147-173.

Martins-Neto M.A., Pedrosa-Soares A.C. \& Lima S.A.A. 2001 Tectono-sedimentary evolution of sedimentary basins from Late Paleoproterozoic to Late Neoproterozoic in the São Francisco craton and Araçuaí fold belt, eastern Brazil. Sed. Geol., 141/142: 343-370.

Martins-Neto M.A. \& Alkmim F.F. 2001. Estratigrafia e evolução tectônica das bacias neoproterozóicas do paleocontinente São Francisco e suas margens: Registro da quebra de Rodínia e colagem de Gondwana. In: C.P. Pinto \& M.A. Martins-Neto (eds.) Bacia do São Francisco: Geologia e Recursos Naturais, SBG/Núcleo MG, pp.: 31-54.

Martins-Neto M.A. \& Hercos C.M. 2002. Sedimentation and tectonic setting of Early Neoproterozoic glacial deposits in southeastern Brazil. In: W. Alterman \& P.L. Corcoran (eds.) Precambrian Sedimentary Environments: a modern approach to ancient depositional system. (Special Publication of the International Association of Sedimentologists, IAS- Blackwell.).

Martins-Neto M.A. 2005. A Bacia do São Francisco: Arcabouços estratigráfico e estrutural com base na interpretação de dados de superfície e subsuperfície. In: SBG, Simp. Craton São Francisco, 3, Salvador, Anais, p. 283-286.

Muzzi Magalhães P. 1989. Análise estrutural qualitativa das rochas do Grupo Bambuí, na porção sudoeste da Bacia do São Francisco. Dissertação de Mestrado, Departamento de Geologia da Escola de Minas, Universidade Federal de Ouro Preto, $100 \mathrm{p}$.

Muzzi Magalhães P., Chemale Jr. F. \& Alkmim F.F. 1989. Estilo tectônico da porção sudoeste da Bacia do São Francisco. In: SBG/MG, Simp. Geol. Minas Gerais, 5, Belo Horizonte, Anais, p. 284-288. (Boletim 10).

Oliveira F.V. 1994. Estilo estrutural e curvatura da zona limítrofe do Cráton do São Francisco, nas regiões de Presidente Juscelino e Cardeal Mota, MG. Dissertação de Mestrado, Departamento de Geologia da Escola de Minas, Universidade Federal de Ouro Preto, 128 p.
Pedrosa Soares A.C. \& Wiedeman-Leonardos C. 2000. Evolution of the Araçuaí belt and the connection to the Ribeira belt, eastern Brazil. In: U.G. Cordani, E.J. Milani, A. Thomaz Filho \& D.A. Campos (eds.) Tectonic Evolution of South America. Rio de Janeiro, Brazil, pp.: 265-285.

Pedrosa-Soares A.C., Cordani U.G. \&Nutman A. 2000. Constraining the age of Neoproterozoic glaciation in Eastern Brazil: First U-Pb (SHRIMP) data of detrital zircons. Rev. Bras. Geoc., 30: 58-61.

Pedrosa Soares A.C., Noce C.M., Wiedeman C.M. \&Pinto C.P. 2001. The Araçuaí-West-Congo Orogen in Brazil: an overview of a confined orogen formed during Gondwanaland assembly. Precambrian Res., 110(1-4): 307-323.

Pereira L.F. 1992. Relações tectono-estratigráficas entre as unidades Canastra e Ibiá na região de Coromandel, MG. Dissertação de Mestrado, Instituto de Geociências, Universidade de Brasíllia, 73 p.

Pimentel M.M., Fuck R.A. \& Botelho N.F. 1999. Granites and the Geodynamic of the Neoproterozoic Brasília belt, central Brazil: a review. Lithos, 46: 463-483.

Pimentel M.M., Fuck R.A., Jost H., Ferreira Filho C.F. \& Araújo S.M. 2000. The basement of the Brasília fold belt and the Goiás Magmatic Arc. In: U.G. Cordani, E.J. Milani, A. Thomaz Fo \& D.A. Campos (eds.) Tectônic Evolution of South America. Rio de Janeiro, pp.: 195-230. (Intern. Geol. Congr., 31).

Romeiro Silva P.C. \& Zalán P.V. 2005. Contribuição da sísmica de reflexão na determinação do limite oeste do Cráton do São Francisco. In: SBG, Simp. Craton São Francisco, 3, Salvador, Anais, p. 44-47.

Romeiro Silva P.C., Braun O.P.G., Zalán P.V., De Paula L. \& Martins M. 1998. São Francisco Basin - Exploration Frontier for Gás in Central Brazil. In: AAPG International Conference, Extended Abstracts, p. 990-991.

Sawasato E.Y. 1995. Estruturação da porção meridional da bacia Alto-Sanfranciscana, Cretáceo do Oeste de Minas Gerais. Dissertação de Mestrado, Departamento de Geologia, Escola de Minas, Universidade Federal de Ouro Preto, $127 \mathrm{p}$.

Sgarbi G.N.C., Sgarbi P.B.A, Campos J.E.G., Dardenne M.A. \& Penha U.C. 2001. Bacia Sanfranciscana: O Registro Fanerozóico da Bacia do São Francisco. In: C.P. Pinto \& M.A. Martins-Neto (eds.) Bacia do São Francisco: Geologia e Recursos Naturais, SBG/Núcleo MG, pp.: 93-138.

Uhlein A. 1991. Transição cráton-faixa dobrada: um exemplo do Cráton do São Francisco e da Faixa Araçuaí (ciclo Brasiliano) no estado de Minas Gerais. Tese de Doutorado, Instituto de Geociências, Universidade de São Paulo, $295 \mathrm{p}$.

Valeriano C.M. 1999. A Faixa Brasília Meridional com ênfase no segmento da represa de Furnas: Modelos de evolução tectônica. Tese de Livre Docência, Faculdade de Geologia, Universidade do Estado do Rio de Janeiro, 89 p.

Manuscrito CSF-05

Submetido em 22 de maio de 2006 Aceito em 30 de março de 2007 